\title{
SCIENCE TEACHERS' BELIEFS ABOUT USING INQUIRY-BASED LEARNING STRATEGY IN THEIR CLASSROOM PRACTICES

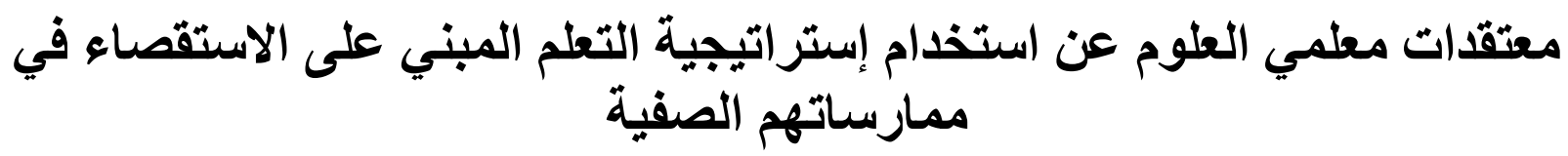

\author{
علي بن سالم بن سيف الحارثي \\ Harthy Ali Salim Saif ${ }^{1 *}$, and Fouad Mahmoud Mohammed Rawash ${ }^{2}$ \\ ${ }^{1} \mathrm{Ph}$.D. Candidate at the Faculty of Education, International Islamic University Malaysia (IIUM) \\ Ali_alharthi@hotmail.com \\ ${ }^{2}$ Assoc. Prof. Dr. at the Faculty of Education, International Islamic University Malaysia (IIUM); \\ fouad@iium.edu.my \\ ${ }^{*}$ Corresponding Author
}

\begin{abstract}
This quantitative study aimed at exploring the beliefs about the use of the inquiry-based learning strategy. Where the researcher found that there is a major deficiency in the classroom practice of the survey strategy, and that the old thought is still in control of the modern science teacher, and there are teachers who do not accept the results that students obtain through their investigative activities if they differ with the result that he wants, or that recorded in Guide. The study adopted the descriptive method, the tool for data collection is; a scale for measuring of beliefs based on the theory of planned behavior (Ajzen, 1991) consists of (45) items, distributed in (3) axes. The findings indicated that: the mean score of science teachers' beliefs on the use of inquiry-based learning strategy was (14.20), which reflects a positive belief and intention within teachers to use the inquiry-based learning strategy. The study also pointed to a positive attitude towards the use of the strategy as the mean score of the behavioral beliefs was (17.01) .In addition, the study revealed a social impact as the mean score of the normative beliefs was (10.06) with a weakness in behavioral controlling as the mean score of control beliefs was $(-12.87)$.
\end{abstract}

Keywords: beliefs, science teachers, learning strategy, inquiry.

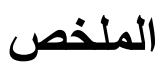

هدفت هذه الدر اسة الكمية إلى تقصي معتقدات معلمي العلوم عن استخدام إستر اتيجية التعلم المبني

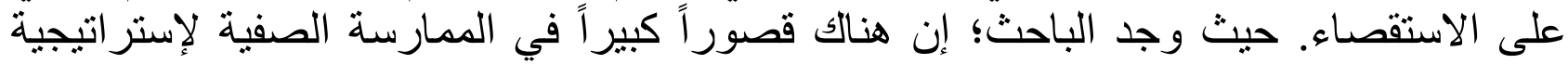

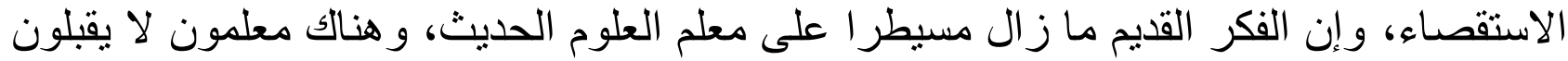

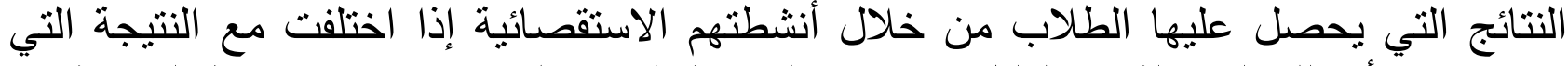

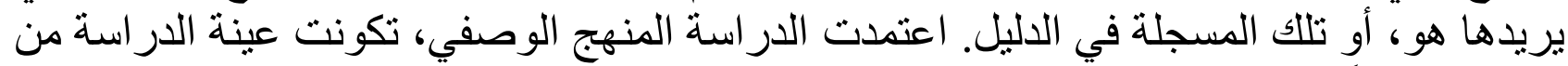

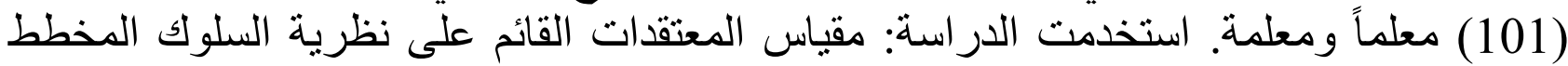

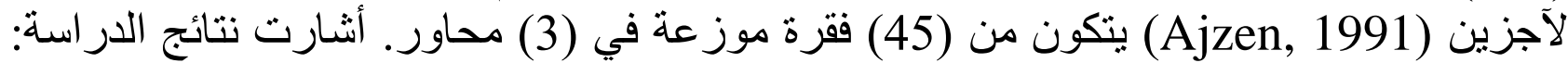
أن منوسط معتقدات معلمي العلوم عن استخدام إستراتيجية التعلم المبني على الاستقصاء بلغ من من 


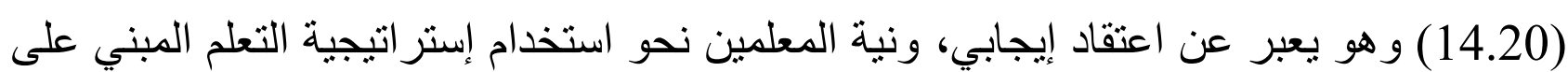

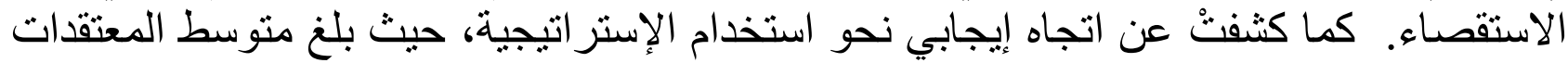

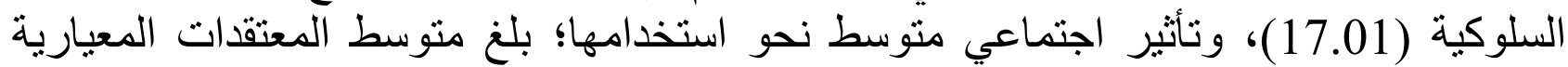

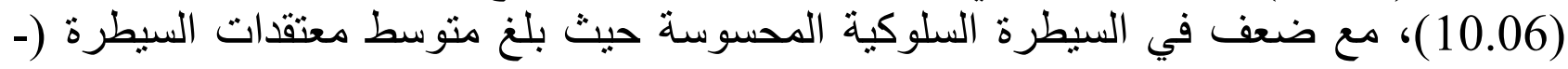

كلمات مفتاحية: معتقدات، معلمو العلوم، إستر اتيجية التعلم، الاستقصاء.

\section{المقدمة:}

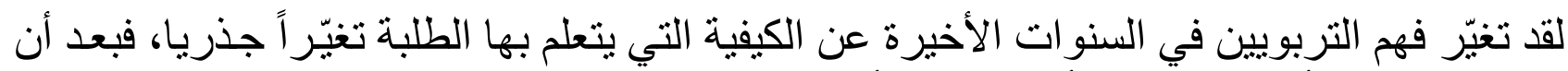

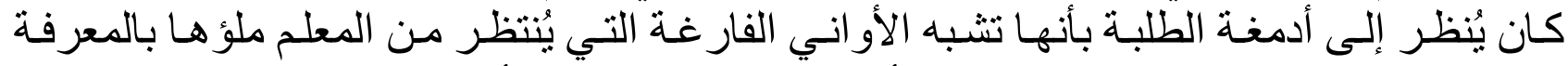

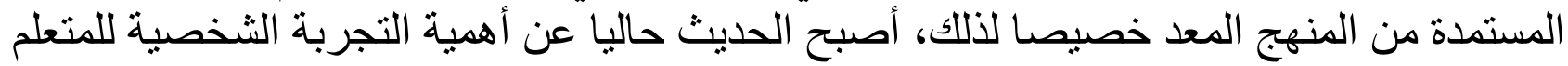

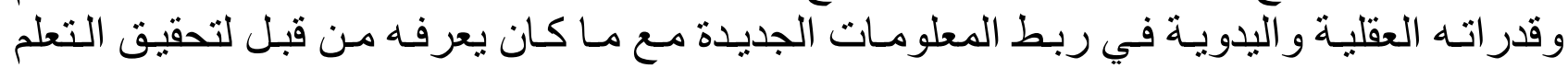

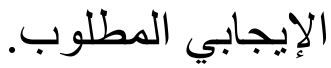

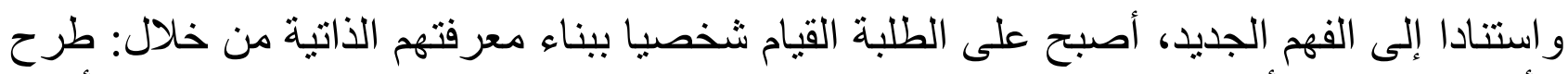

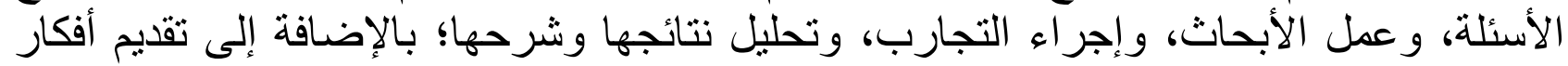
تجريدية لإعادة التفكير في فرضياتهم، وبذلك يكونون متحملين مسؤولية تعلمهم على نحو فئّال

.(Jarrett, 1997)

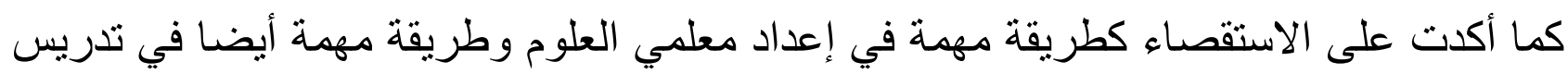

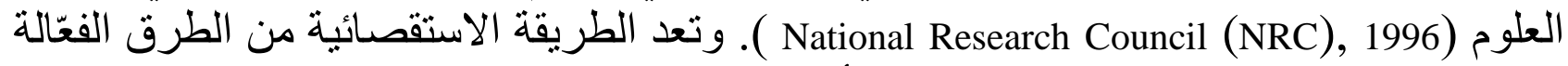

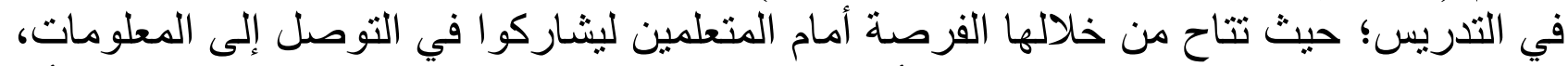

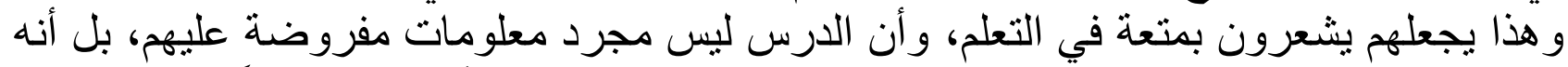

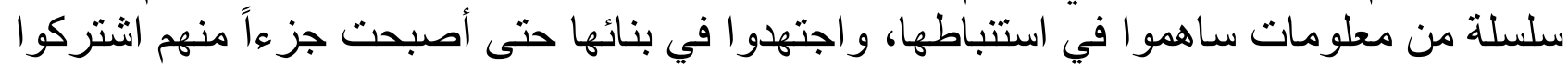
مع المعلم في اكتشافها. (فر ج؛ سلامة سئ؛ و الميهي، 1999).

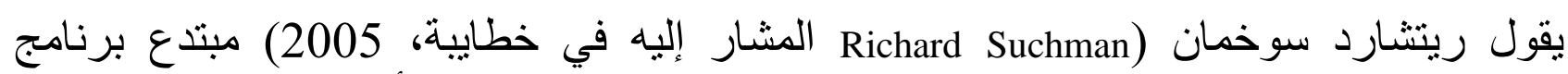

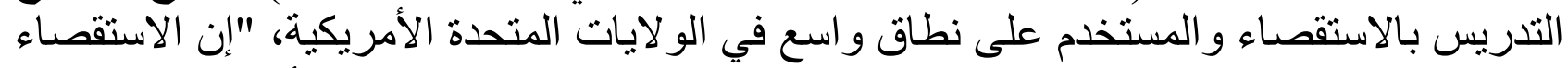

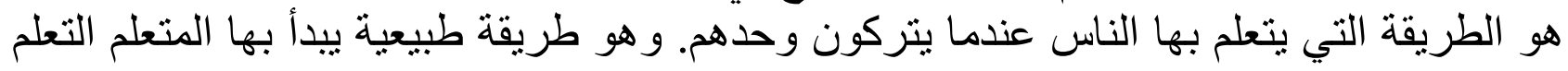
عن البيئة." (ص الطريفة (195) (195).

ويعرف هيرون (Herron المشار إليه في (Al-Balushi, 1998 ) الاستقصاء بأنه "طريقة التعلّم التي

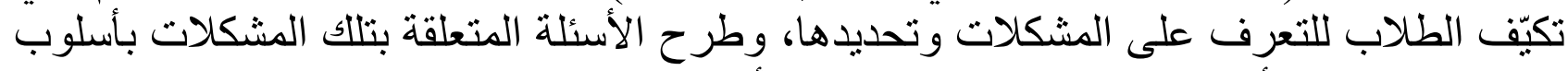

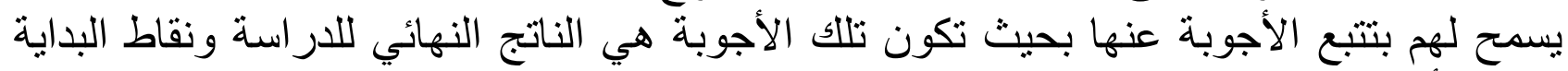

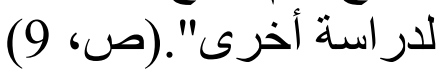

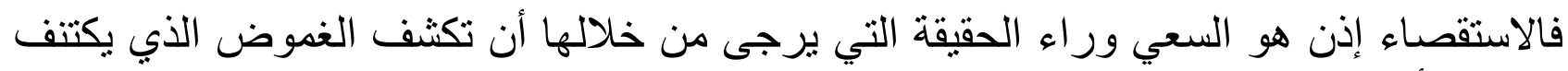

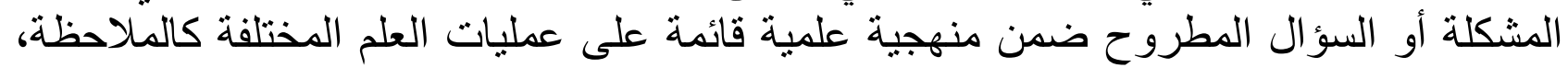

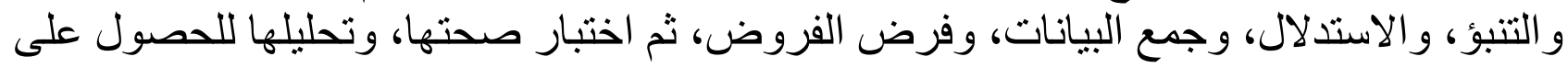


النتائج و تفسير ها.

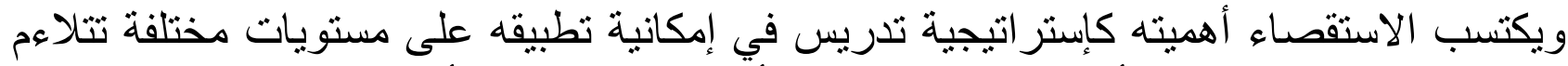

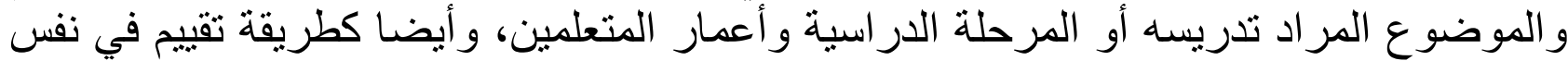

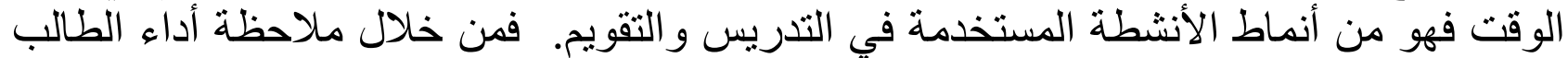

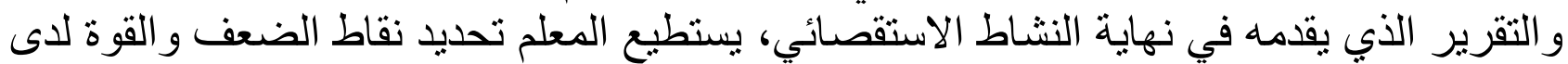

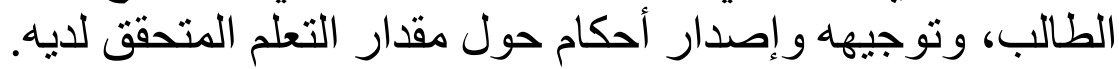

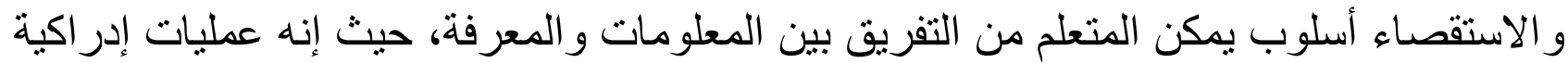

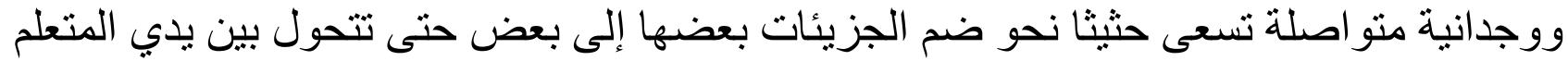

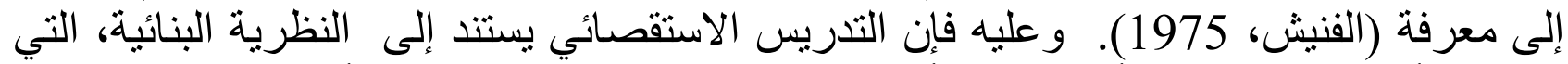

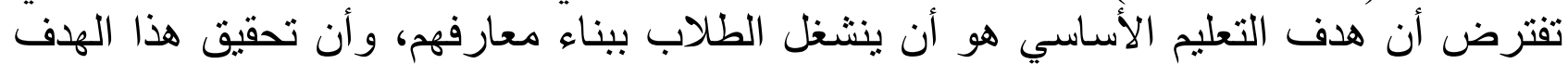

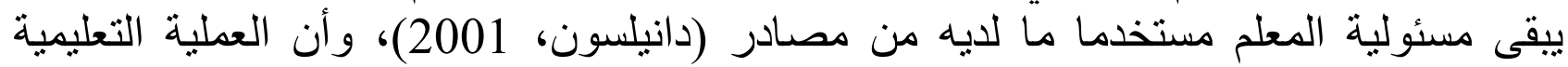

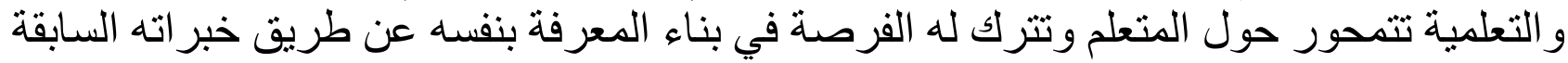

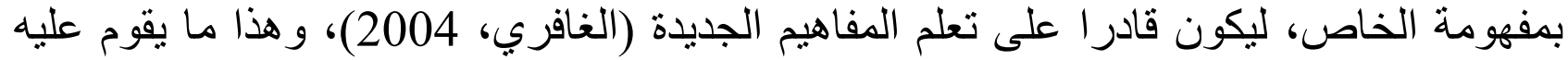

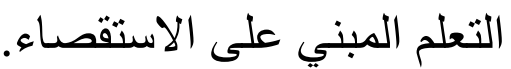

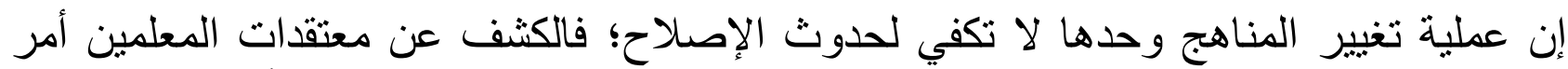

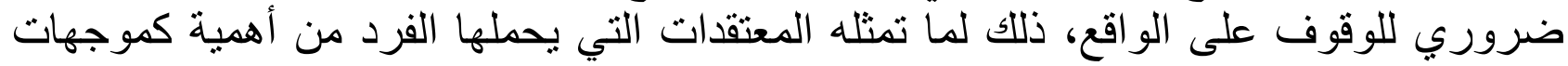

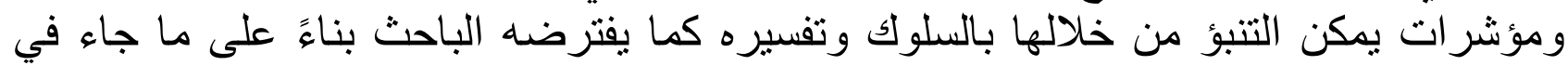

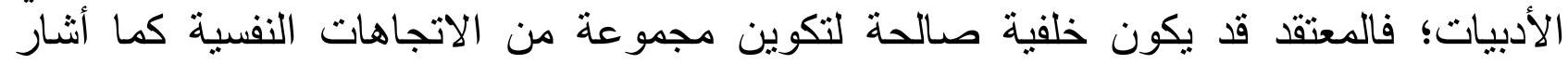

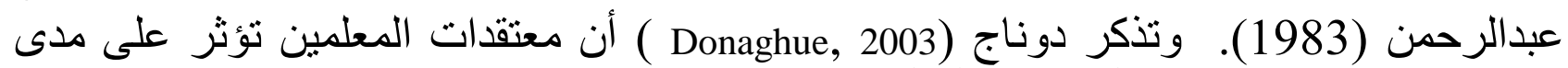
تقبلهم بما يستجد من مداخل أو تقنيات أو أنشطة، وبالتالي فهي تقوم بدور مهم في تطوير المعلم.

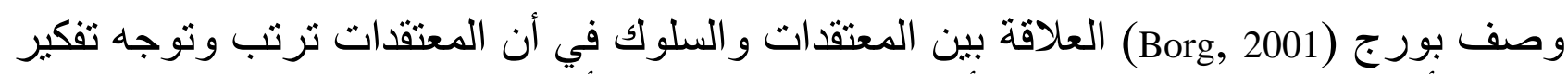

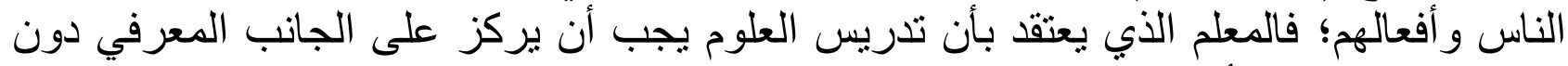

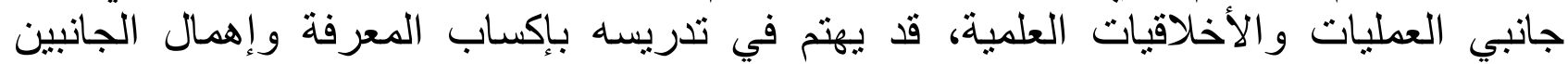

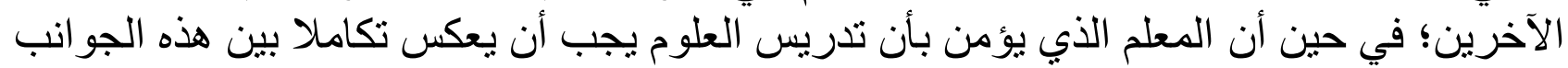

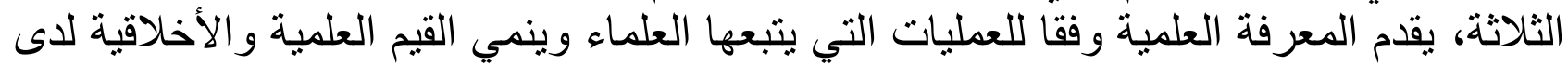

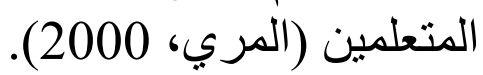

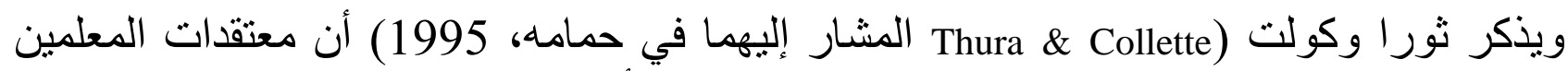

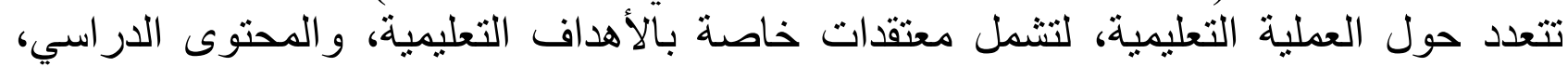

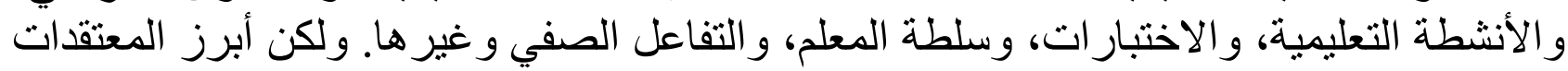

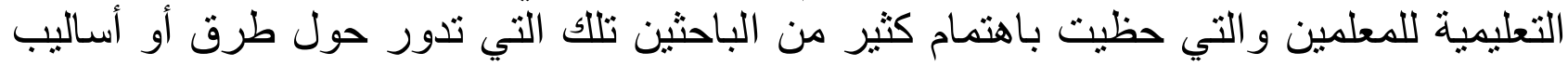
التدريس.

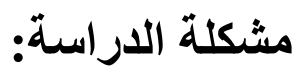

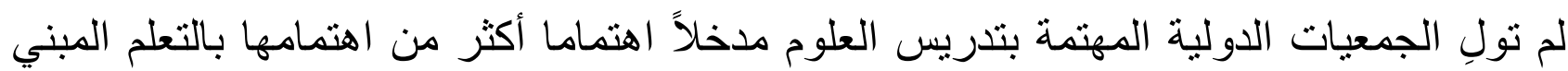

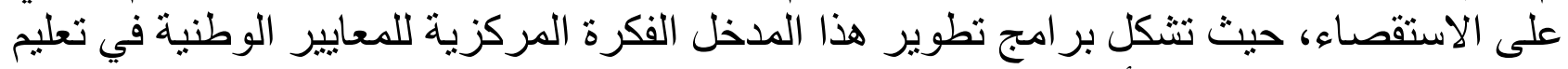

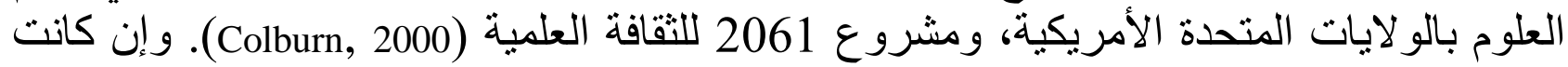


النظرة الحديثة لا تزكي مدخلاً واحداً في التدريس على غيره، إلا أن الاستقصاء العلمي يقع في

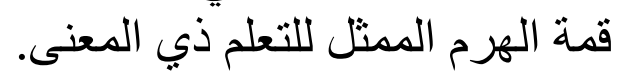

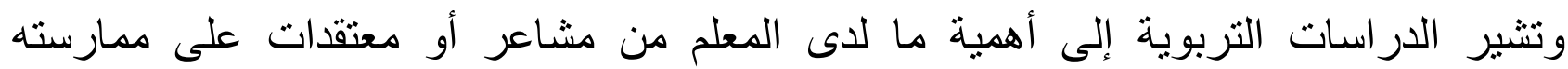

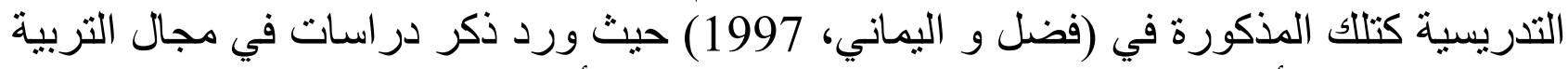

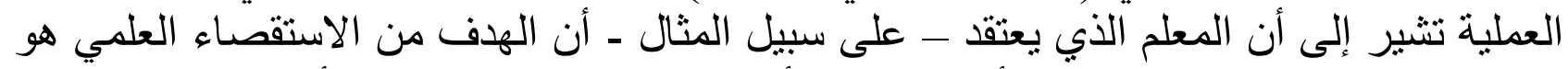

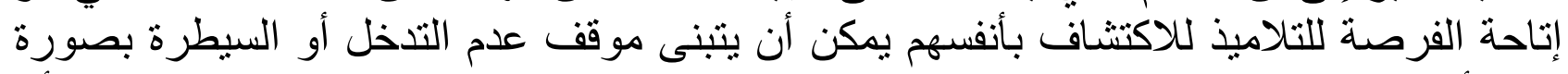

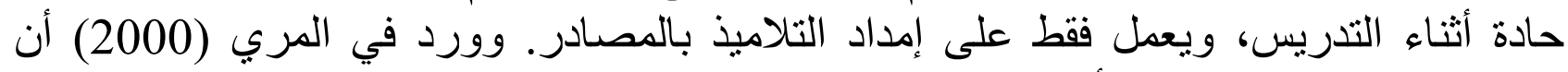

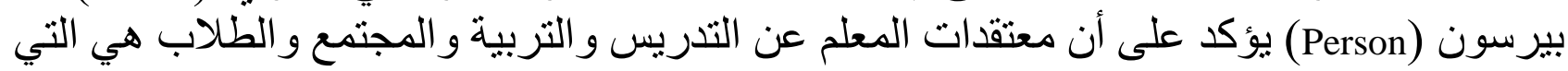

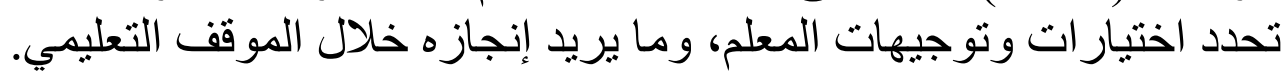

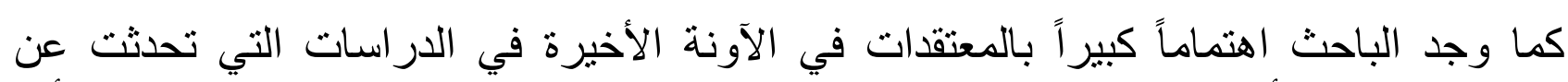

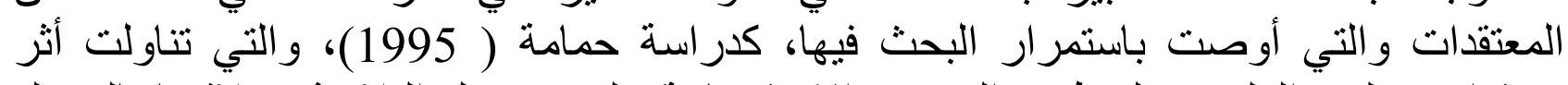

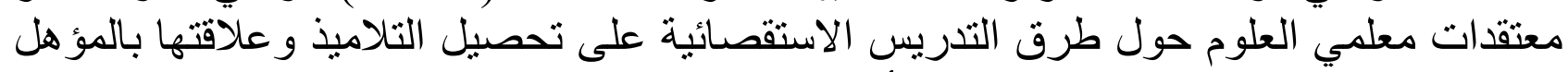

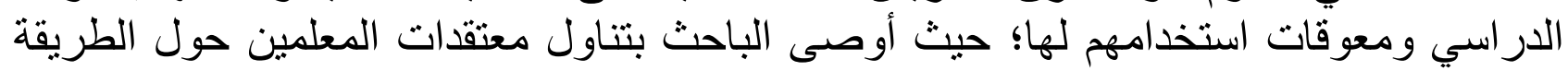

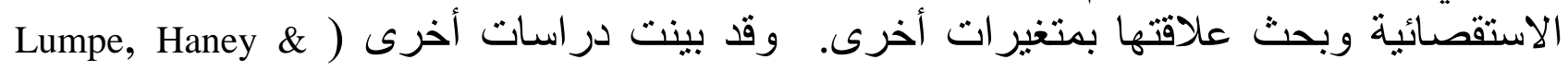

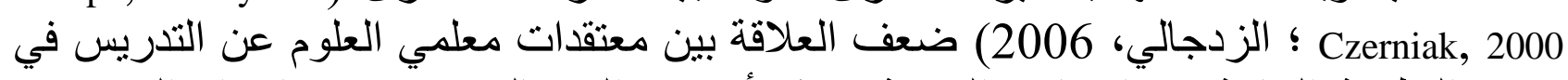

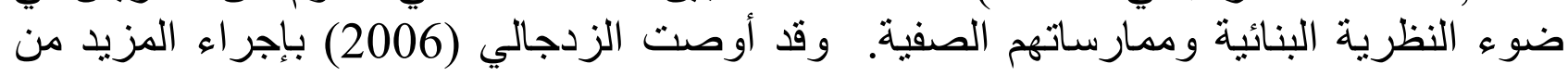

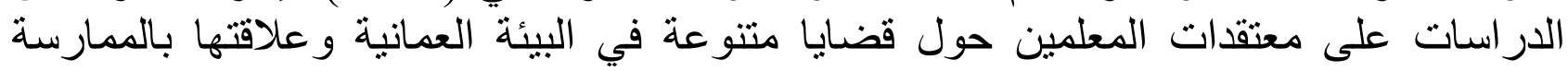

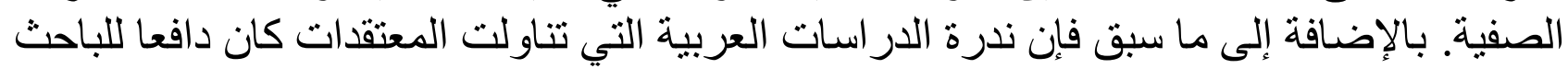

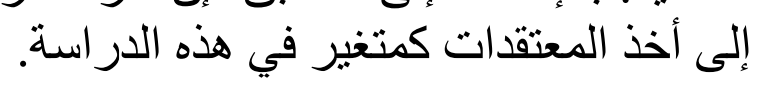

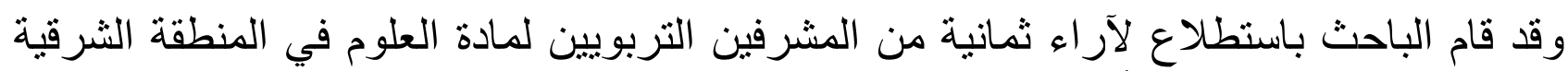

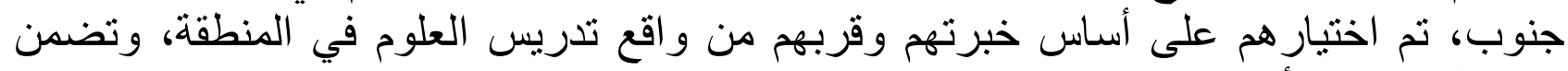

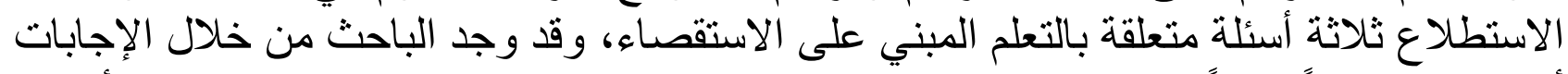

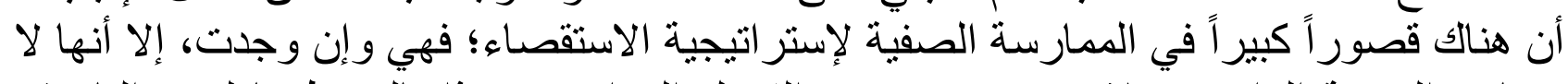

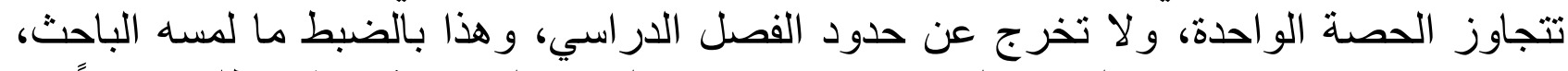

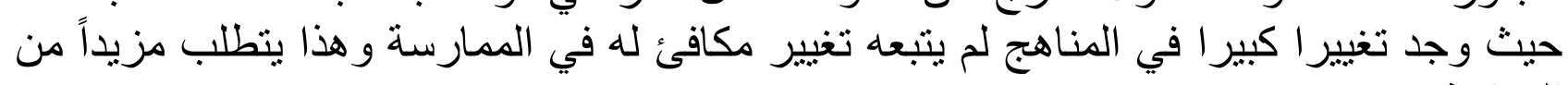
الدراسة.

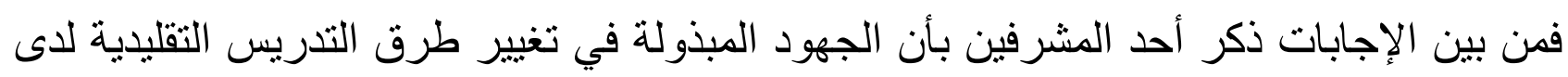

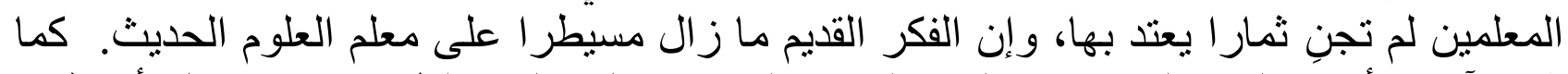

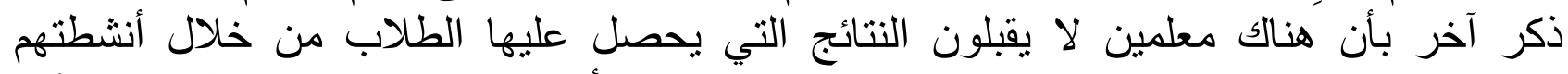

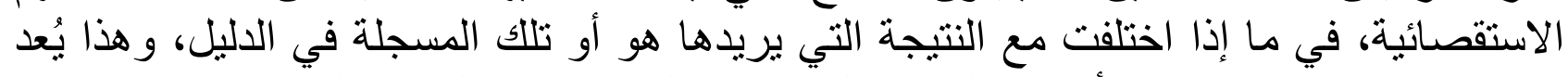

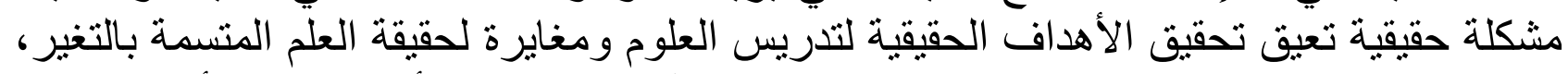

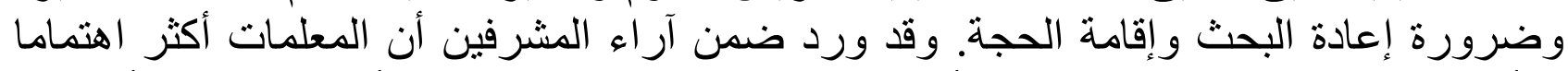

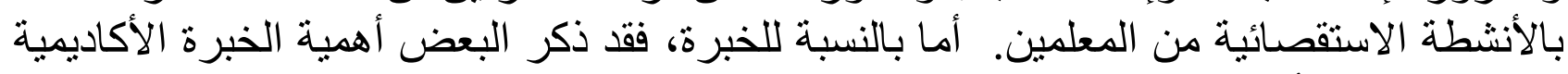

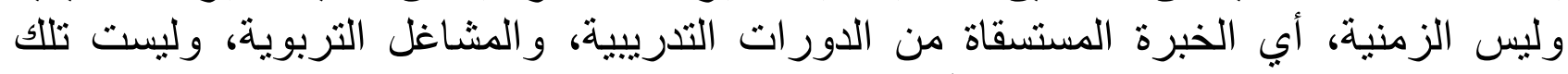

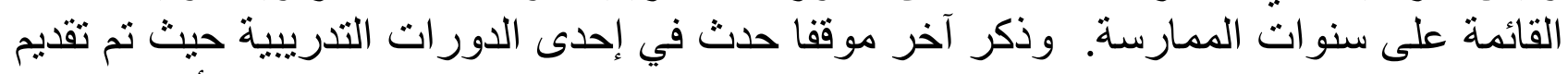

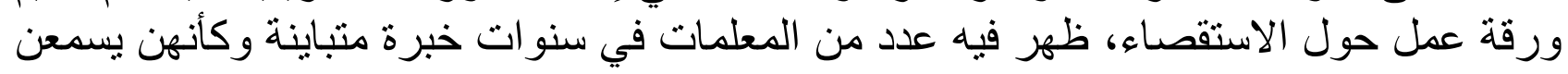


عن الأمر للمرة الأولى. وقد أكد المشرفون جميعا أهمية هذه الدراسة في الكثف عن الأف الأسباب

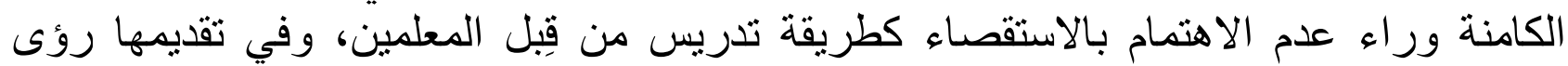

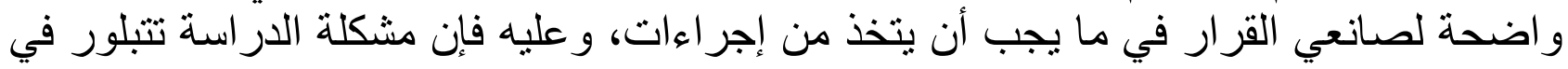

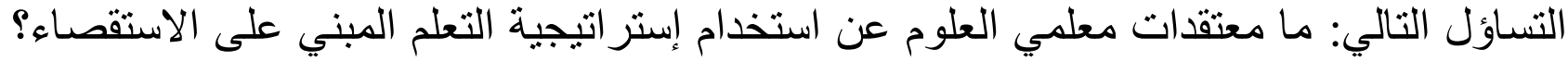
وما علاقتها بممارساتهم الصفية مانف هدف الاراسة هدفت الدراسة إلى: الكثف عن معتقدات معلمي العلوم عن استخدام إستر اتيجية التعلم المبني على الاستقصاء في تدريس العلوم.

الإطار النظري:

يعرّف الاستقصاء العلمي وفق ما جاء في معايير تعليم العلوم الوطنية بأنه الدمج بين الإنه عمليات

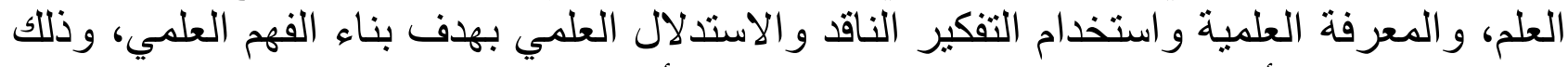

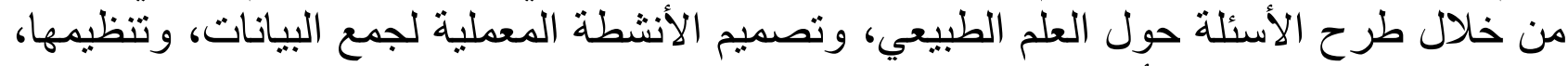

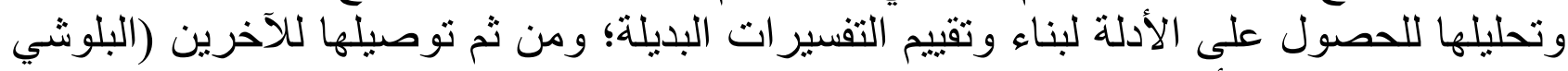

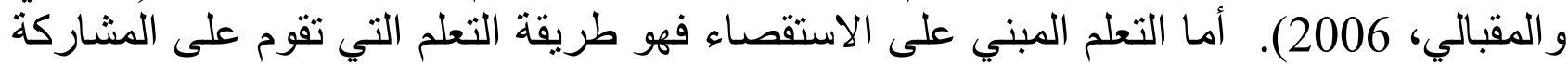

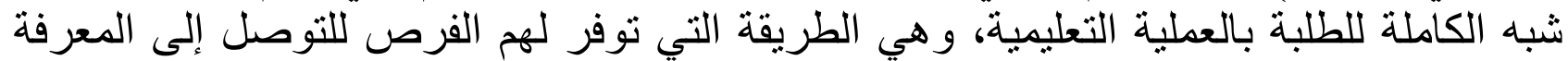
العلمية عن طريق عمليات العلم المختلفة (عطا الله، 2001)

أما المعتقدات يعرفها فيشباين وآجزين (Fishbein, \& Ajzen,1975:131) "بأنها الأحكام الثخصية

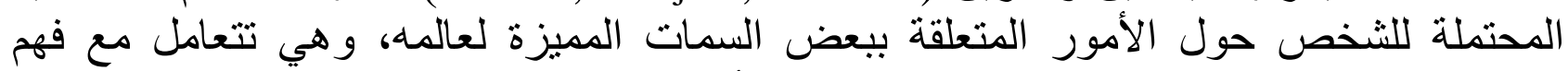

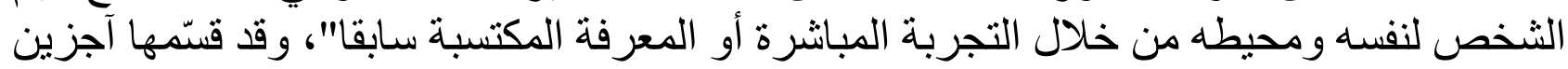
(Ajzen, 1985 , 1988 , 1991 , 2006)

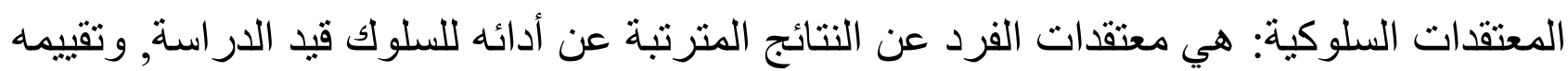

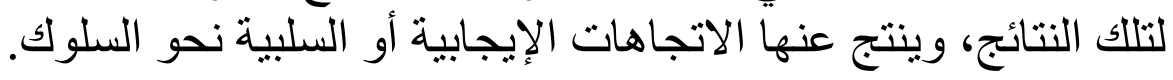

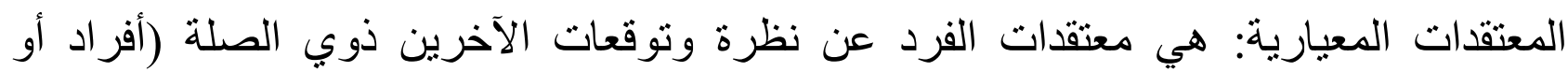

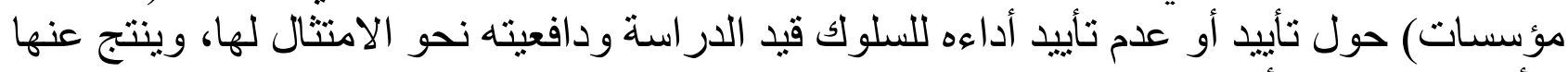

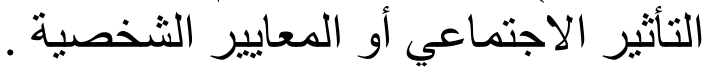

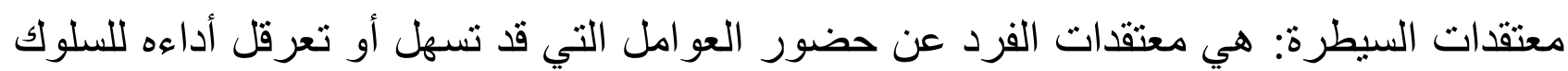

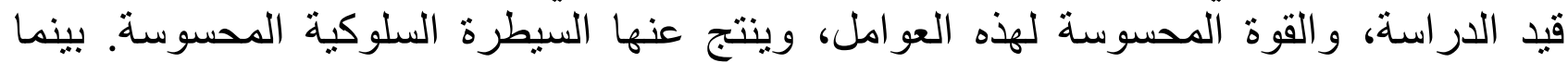

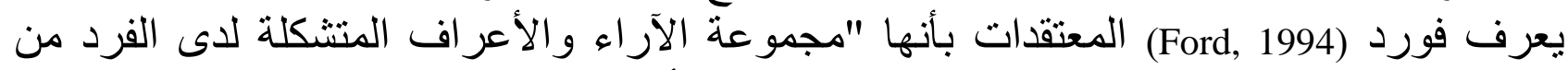

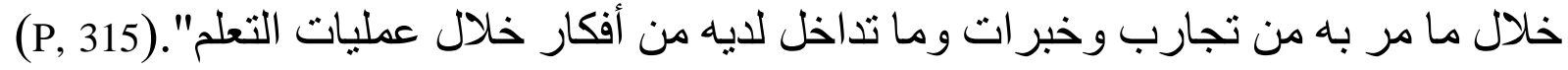

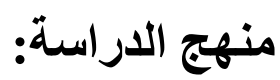

اتُبع المنهج الوصفي التحليلي في تنفيذ هذه الدراسة؛ حيث ثم الكثنف عن معتقدات معلمي العلوم

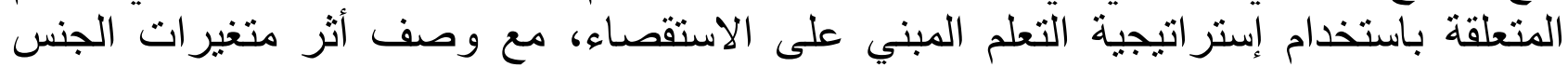

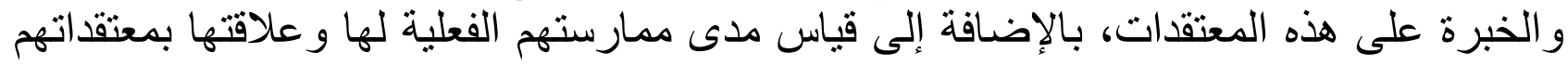
و وتفسير ذلك. 


\section{مجتمع الاراسة وعينتها:}

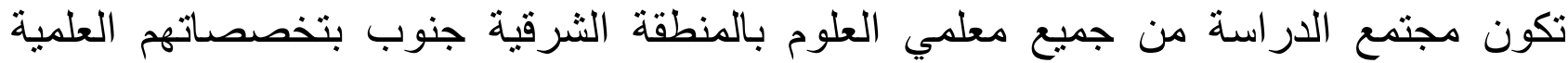

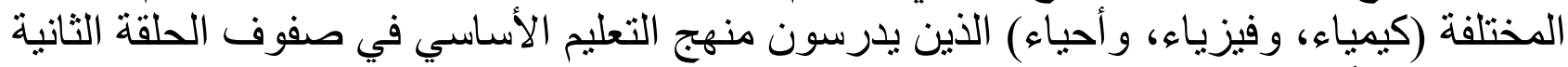

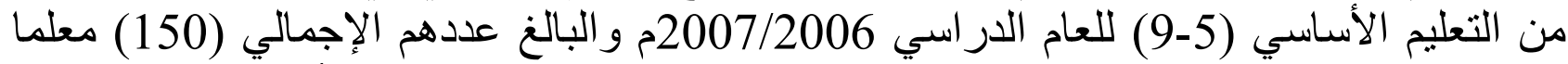

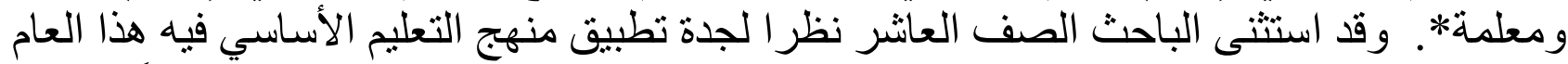

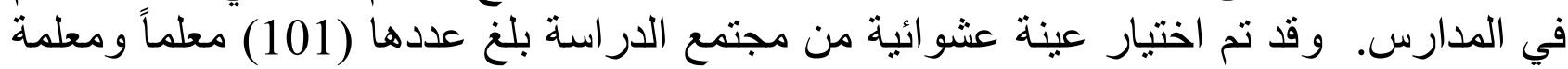

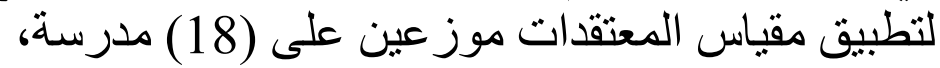

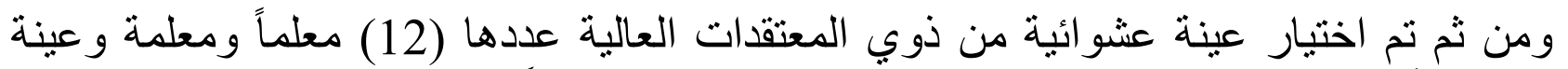

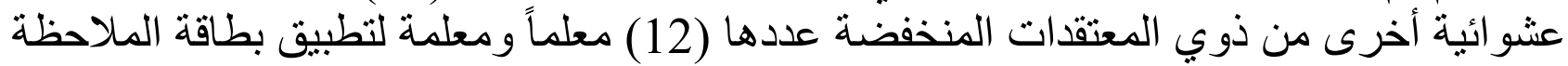

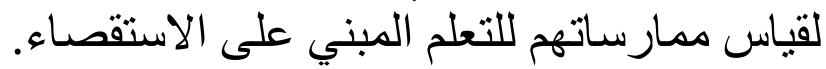

أدوات الدراسة: مقياس معتقدات معلمي العلوم عن استخدام إستراتيجية التعلم المبني على الألى

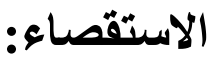

اعتمد الباحث في بناء المقياس على نظرية في علم النفس السلوكي تدعى نظرية السلوك المخطط

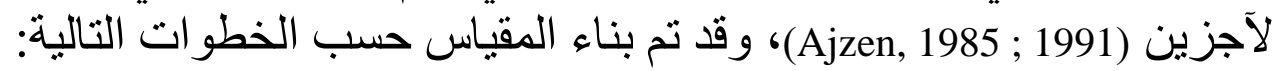

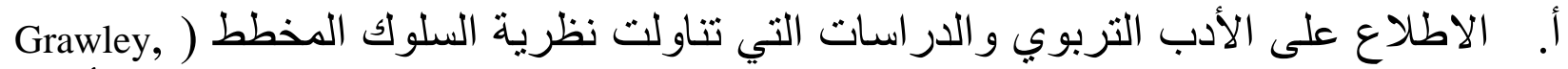

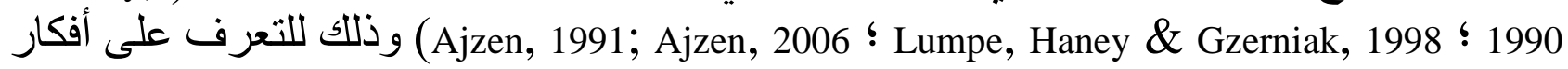

النظرية وتاريخها، و الاستفادة منها في التعرف على كيفية بناء مقياس للمعتقدات وفق متغير اتها.

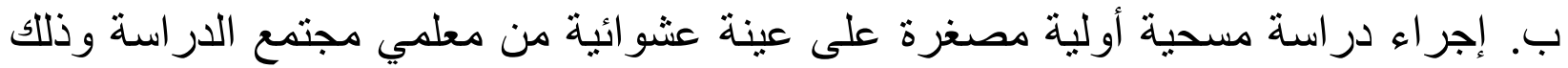

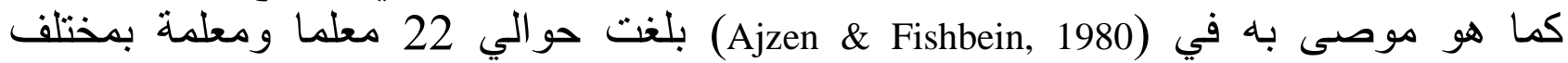

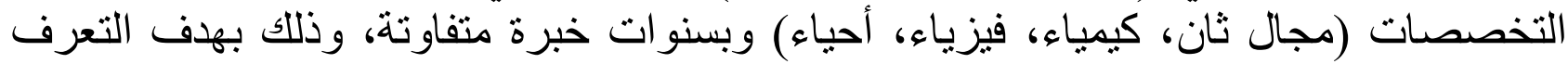

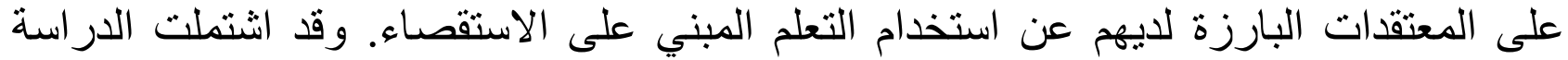

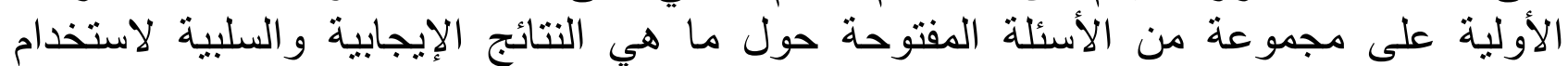

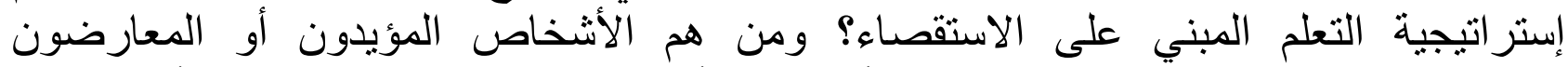

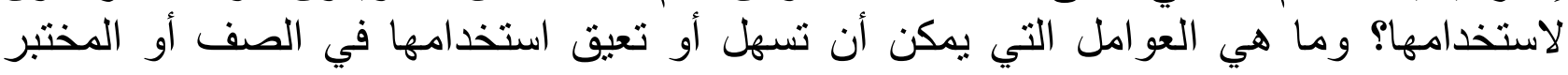

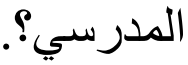

تم بناء المقياس وفقاً للخطوات الآتية:

أ. تحليل استجابات عينة الدر اسة الأولية وانتزاع أكثر المعتقدات البارزة تكر ارا بما يعادل 75\%

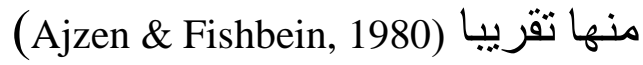

ب. ب. وضع سؤال التقرير الذاتي في عبارة واحدة للتعرف على السلوك الماضي للمستجيبين فيما

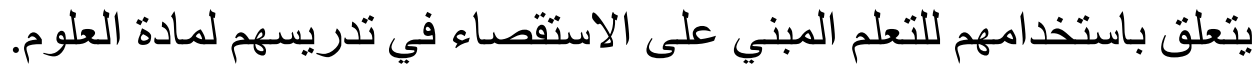

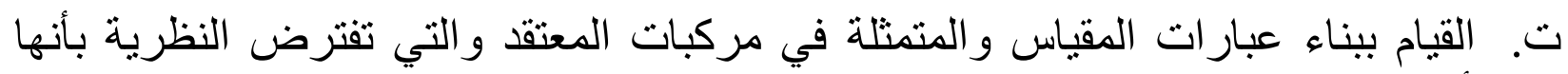

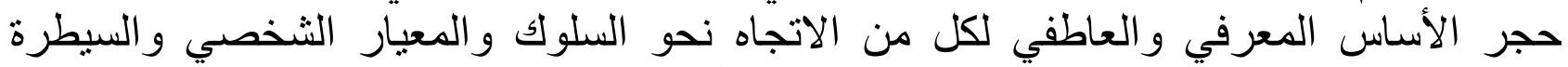

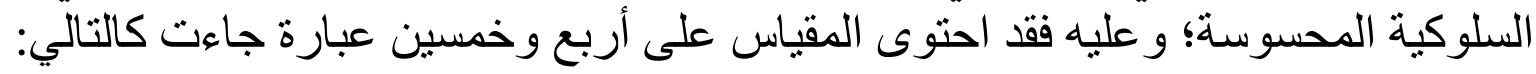

جدول (1) بيان بعدد عبار ات مقياس المعتقدات وفق مركبات النظرية وعنية 


\begin{tabular}{|c|c|c|c|}
\hline عدد & \multicolumn{2}{|c|}{ نوع المعتقدات } & 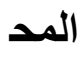 \\
\hline 11 & أولاً: قوة الاعتقاد بالنتيجة & \multirow{2}{*}{ المعتقدات السلوكية } & \multirow{2}{*}{1} \\
\hline 11 & ثانياً: تقييم النتيجة & & \\
\hline 6 & ثالثاً: قوة الاعتقاد بتأييد الآخرين & \multirow{2}{*}{ المعتقدات المعيارية } & \multirow{2}{*}{2} \\
\hline 6 & رابعاً: الدافعية نحو الامتثال & & \\
\hline 10 & خامساً: قوة الاعتقاد بحضور & \multirow{2}{*}{ معتقدات السيطرة } & \multirow{2}{*}{3} \\
\hline 10 & سادساً :القوة المحسوسة للعامل & & \\
\hline 54 & 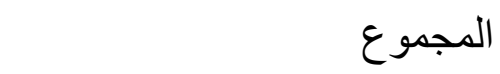 & & \\
\hline
\end{tabular}

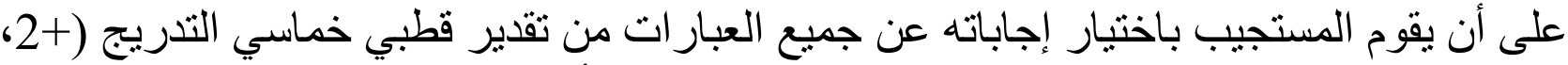

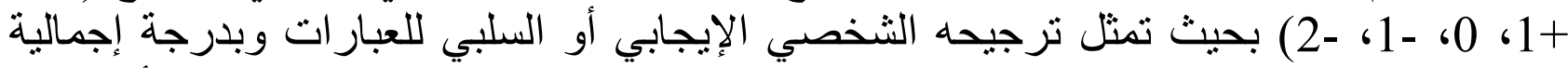

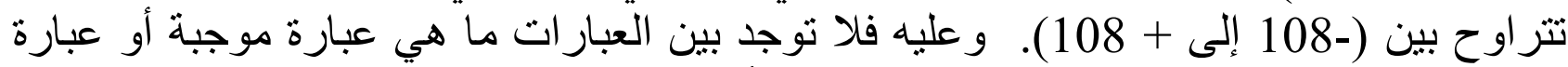

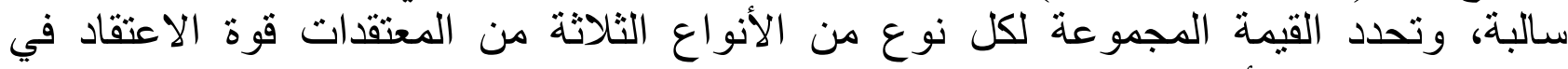
الاتجاهين الإيجابي أو السلبي.

وقد تكونت الأداة في صورتها الأولية من (3) محاور موضحة في الجدول أعلاه، و(55) عبارة.

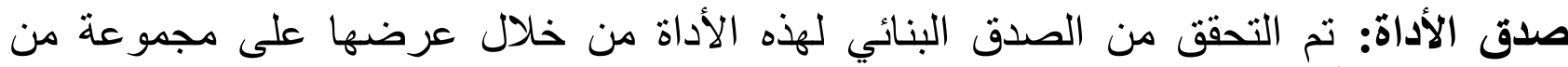

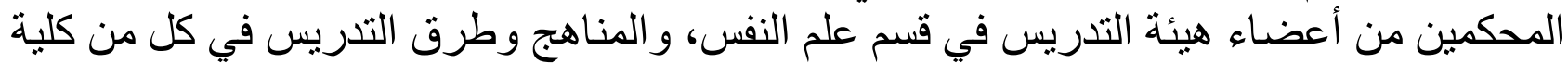

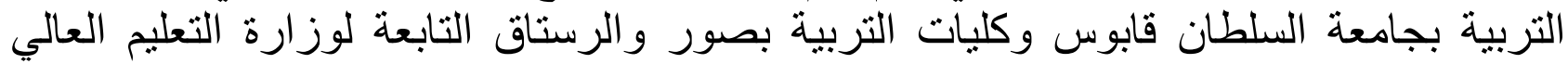

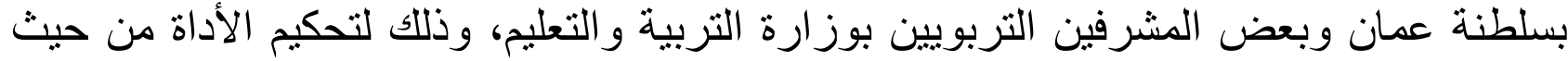

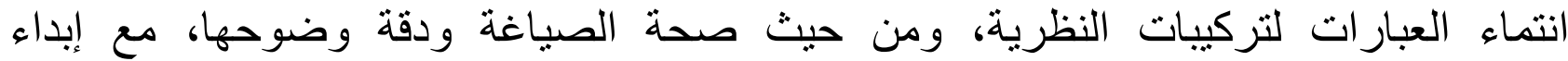

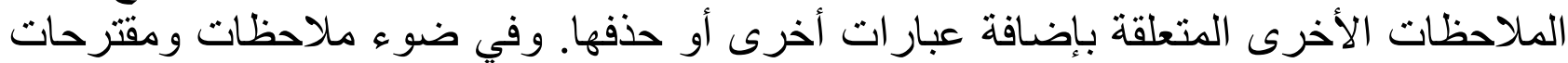
المحكمين تم إعادة صباغة بعض العبار الفاته وحذف عبار ات أخرى أخرى

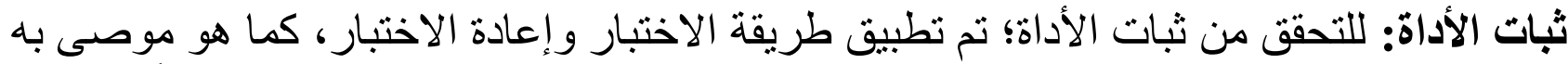

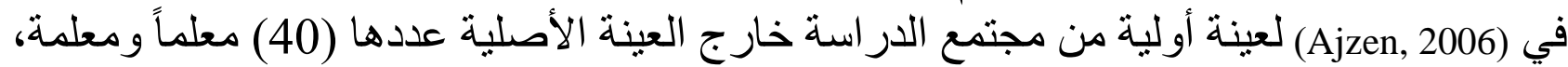
وكانت المدة الزمنية الفاصلة بين التطبيقين أسبو عين للتحقق من الثبات في طريقة إعادة الإنة الاختبار،

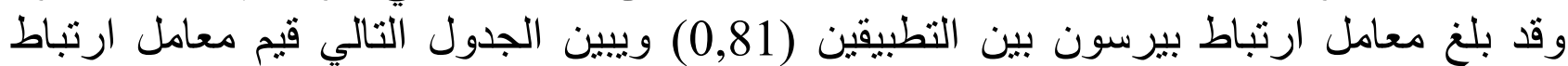
بيرسون لمحاور الأداة الثلاثة ولمجنمل بلمن الأداة:

جدول (2) قيم معاملات ارتباط بيرسون لمحاور الأداة الثناثة ولمجمل الأداة لحساب الثبات

\begin{tabular}{|l|c|c|c|c|c} 
& محاور الأداة & & \\
\end{tabular}


IJASOS- International E-Journal of Advances in Social Sciences, Vol. VI, Issue 16, April 2020

\begin{tabular}{|c|c|c|c|c|c|}
\hline الارتباط & الثاني & الأول & & & \\
\hline$* * 0,72$ & 14,6 & 16,6 & 44-44- & 22 & المعتقدات السلوكية \\
\hline$* * 0,82$ & 10,5 & 10 & 24-24- & 12 & المعتقدات المعيارية \\
\hline$* * 0,74$ & 15,9 & $16,6-$ & $40-40-$ & 20 & معتقدات السيطرة \\
\hline$* * 0,81$ & 9,2 & 10 & 108 - 108- & 54 & مجموع المعتقدات (مجمل الأداة) \\
\hline
\end{tabular}

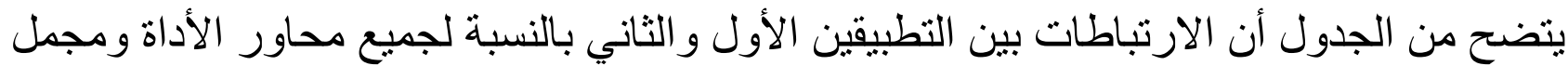
الأداة تعادل أو تزيد عن 0,72 و هو مقبول تربويا، مما يدل على على ثبات الإن الأداة و إمكانية الاعتماد

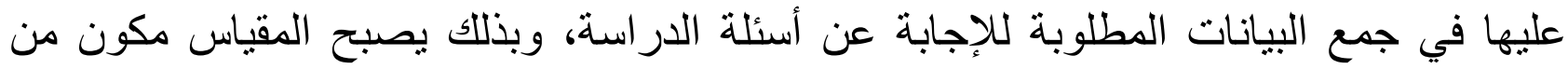

استخدم الباحث التحليل الوصفي: حيث تم حساب الإتوسطات الحسابية والانحر افات المعيارية

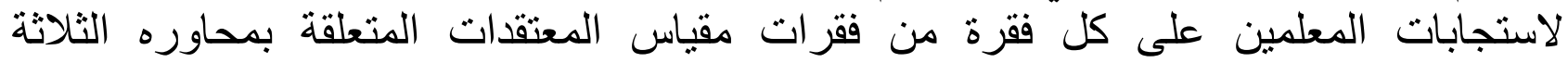

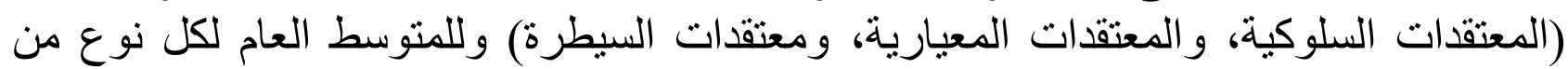

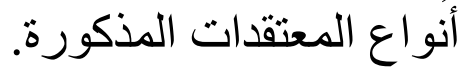
نتائج الدراسة:

ما معتقات معلمي العلوم بمدارس التعليم الأساسي عن استخدام إستراتيجية التعلم المبني على الاستقصاء؟

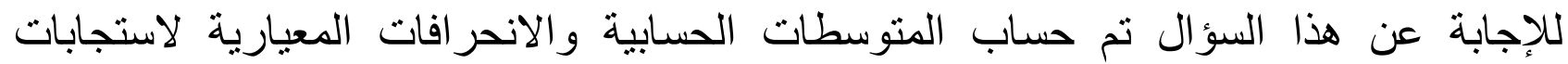

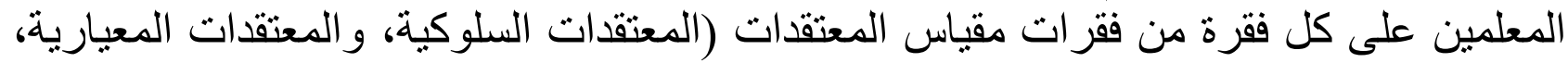

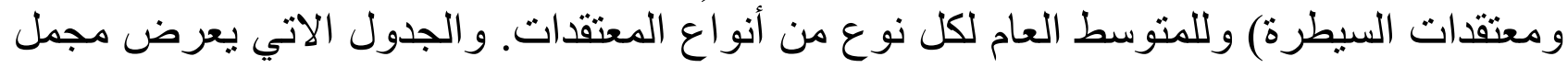

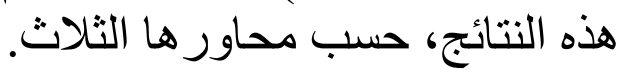

جدول (3) معتقدات المعلمين العامة (السلوكية و المعيارية ومعتقدات السيطرة)

\begin{tabular}{|c|c|c|c|c|}
\hline الانحريافية & الحتوسابية & مدى الدرجة & الفقرات & نوع المعتقدات \\
\hline 7.472 & 17.01 & $(44)-(44-)$ & 11 & السلوكية \\
\hline 7.050 & 10.06 & $(24)-(24-)$ & 6 & المعيارية \\
\hline 10.448 & $12.87-$ & $(40)-(40-)$ & 10 & السيطرة \\
\hline 13.127 & 14.20 & $(108)-(108-)$ & 27 & المعتقدات \\
\hline
\end{tabular}




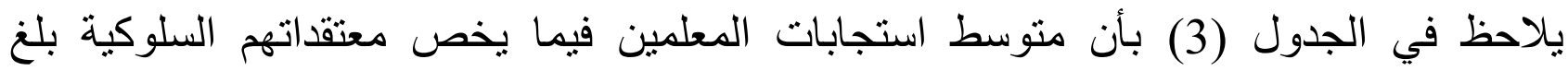

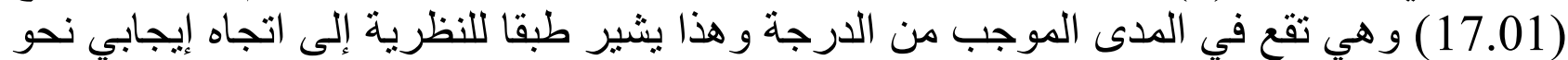

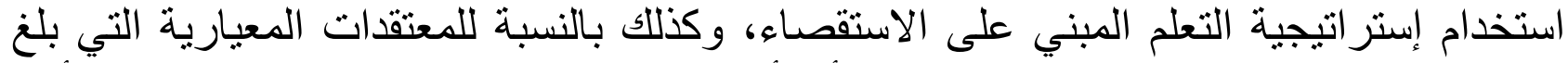

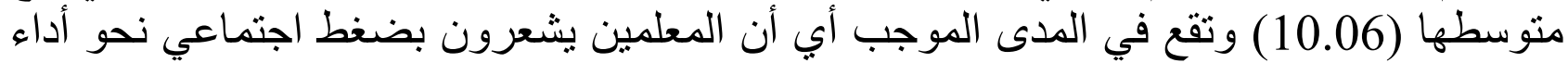

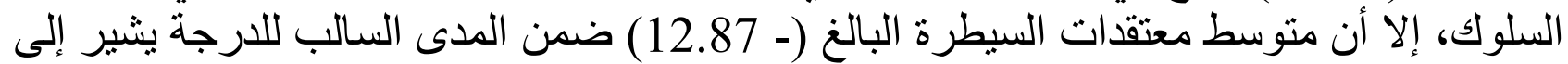

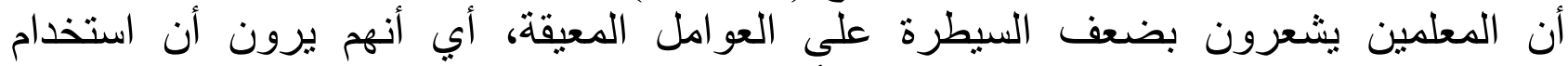

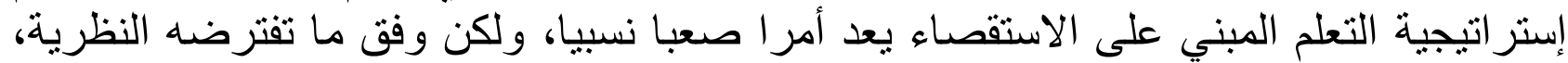

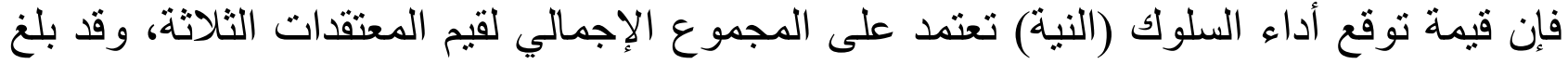

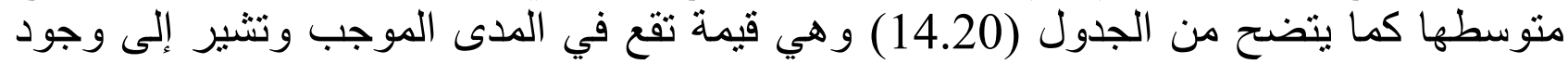

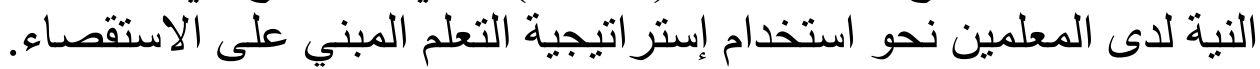

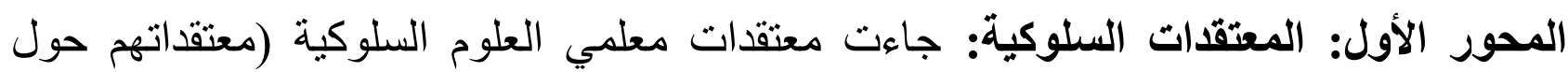

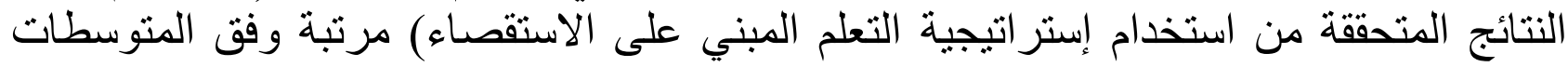
الحسابية كما في الجدول (4): جدول (4) المعتقدات السلوكية لمعلمي العلوم عن استخدامهم للتعلم المبني للاستقصاء في التدريس

\begin{tabular}{|c|c|c|c|}
\hline الالمعياري & الحستوسط & المعتقد السلوكي & $p$ \\
\hline 1,40 & 2,71 & جعل التعلم أكثر متعه و إثارة. & 1 \\
\hline 1,27 & 2,70 & إكساب الطلاب مزيدا من الثقة بالنفس و الدافعية نحو التعلم. & 2 \\
\hline 1,51 & 2,57 & 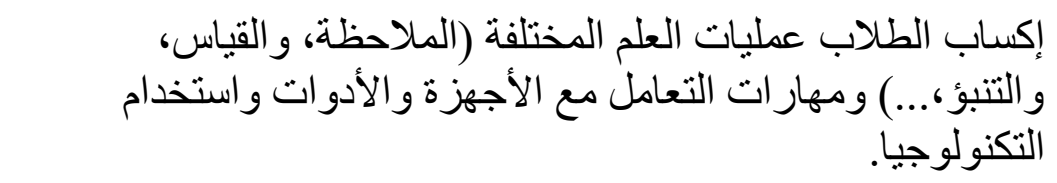 & 3 \\
\hline 1,44 & 2,43 & تحقيق فهم أسر ع و أعمق و أكثر ثباتا لدى الطلاب. & 4 \\
\hline 1,50 & 2,40 & و القسابة الطملاب المهار اتلة الاجتماعية المناسبة كالتعاون و الاتصسال & 5 \\
\hline 1,45 & 0,84 & وقتث. في الخر في الخطة الفصلية نتيجة لما تتطلبه الأنشطة الاستقصائية من & 6 \\
\hline 1,31 & 0,84 & عدم القدرة على التقييم اليومي للطلاب بالثكل الصحيح. & 7 \\
\hline 1,88 & 0,81 & 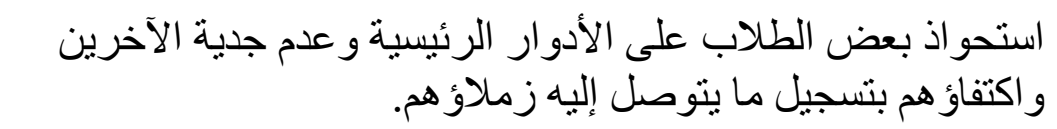 & 8 \\
\hline 1,40 & 0,75 & وتحركه إدارة الصناء العمل. بسبب الفوضى الناتجة عن أسئلة الطلاب الكثيرة & 9 \\
\hline
\end{tabular}




\begin{tabular}{|c|c|c|c|}
\hline 1,43 & 0,50 & و تعرض الأدوات المخلاب لبعضة الأخطار نتيجة تعاملهم المباشر مع الأجهزة & 10 \\
\hline 1,22 & 0,46 & شعور الطلاب بالإحباط نتيجة عدم توصلهم للنتائج المرجوة. & 11 \\
\hline
\end{tabular}

يُلاحظ من خلال الجدول (4) بأن المستجيبين اعتقدوا بتحقق النتائج الإيجابية العبار ات اتلات (1 -5)

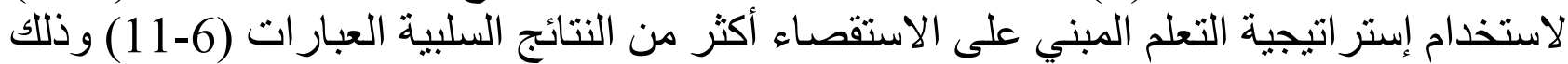

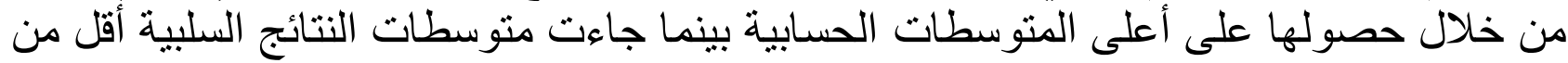
الو احد الصحيح. المحور الثاني: المعتقات المعيارية: أما معتقدات معلمي العلوم المعيارية التي شملت (التوقعات

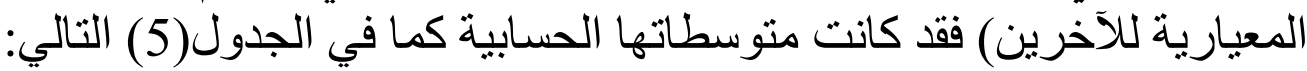
جدول (5) المعتقدات المعيارية لمعلمي العلوم عن استخدام إستر اتيجية التعلم المبني على لمعي الاستقصاء

\begin{tabular}{|c|c|c|c|}
\hline الالحعياري & الحستوسط & الأشخاص ذوي الصلة & p \\
\hline 1,43 & 2,37 & المشرف التربوي. & 1 \\
\hline 1,53 & 2,31 & المعلم الأول. & 2 \\
\hline 1,61 & 1,88 & مدير المدرسة. & 3 \\
\hline 1,50 & 1,23 & الزملاء من المعلمين. & 4 \\
\hline 1,63 & 1,15 & الطلاب. & 5 \\
\hline 1,60 & 1,13 & فني المختبر. & 6 \\
\hline
\end{tabular}

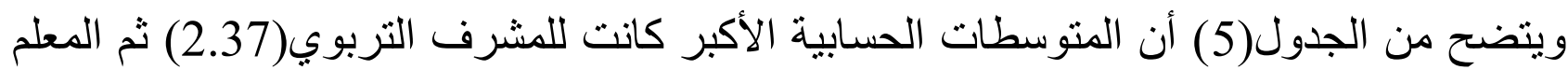

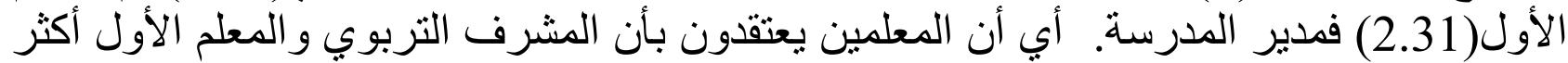

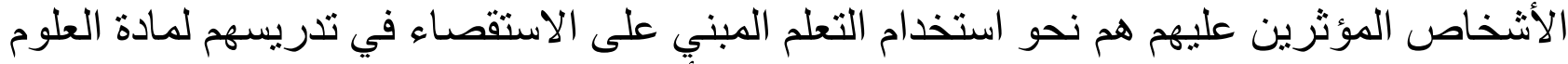

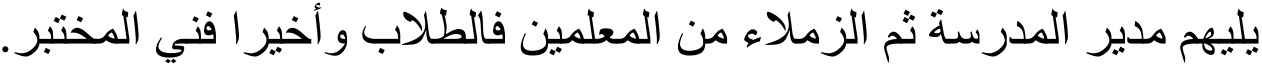
المحور الثالث: معتقات السيطرة: يبين الجدول(6) معتقدات السيطرة لمعلمي العلوم (معتقداتهم

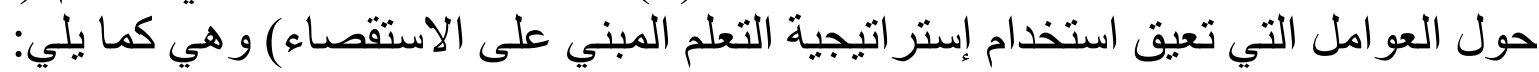
جدول (6) معتقدات السيطرة عن استخدام التعلم المبني على إستر اتيجية التعلم المبني على الى الفي الاستقصاء

\begin{tabular}{|c|c|c|c|}
\hline المعياري & الحستوسي & العوامل & P \\
\hline
\end{tabular}


IJASOS- International E-Journal of Advances in Social Sciences, Vol. VI, Issue 16, April 2020

\begin{tabular}{|c|c|c|c|}
\hline 1.50 & $2.21-$ & كثرة عدد الطلاب في الصف الو احد. & 1 \\
\hline 1.62 & $2.10-$ & زيادة النصاب الأسبو عي من الحصص التدريسية. & 2 \\
\hline 1.68 & $1.98-$ & تعدد الأعباء الإدارية ( السجلات، والأنشطة). & 3 \\
\hline 1.60 & $1.63-$ & وركز النقص في مصادر (مواد التعلم، والأجهزة التعليمية، والأدوات، & 4 \\
\hline 1.47 & $1.26-$ & و وعدم تر افر مر امج التدريب على استخد على الإنماء التعلم الذاتي للقي على الاستقصاء. & 5 \\
\hline 1.82 & $1.15-$ & عدم وجود مختبر مزود بجميع متطلبات التعلم بالاستقصاء. & 6 \\
\hline 1.58 & $0.78-$ & عدم تو افر الوقت الكافي للتخطيط وتتفيذ الأنشطة الاستقصسئية. & 7 \\
\hline 1.30 & $0.58-$ & تباين الطلاب في قدر اتهم العقلية و مهار اتهم العملية. & 8 \\
\hline 1.60 & $0.45-$ & عدم الإلمام بالمهار ات اللازمة للتعلم المبني على الاستقصاء. & 9 \\
\hline 1.90 & $0.44-$ & عدم وجود فني مختبر يساعد على التجهيز والإعداد. & 10 \\
\hline
\end{tabular}

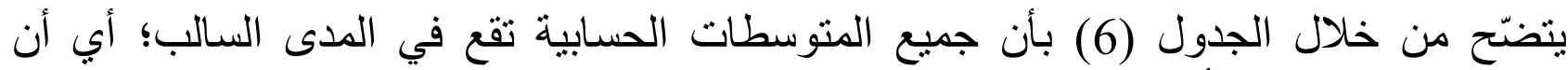

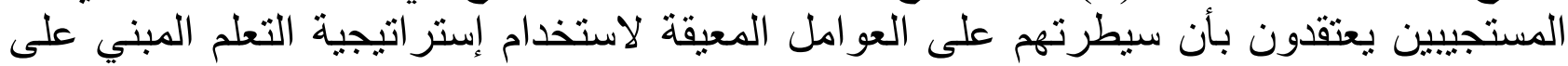

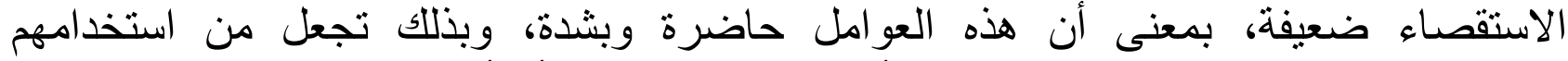

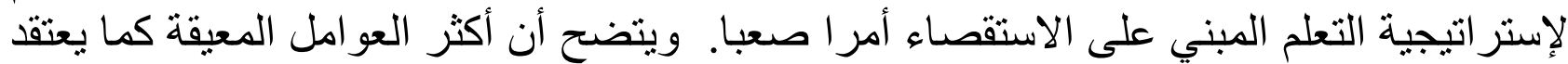

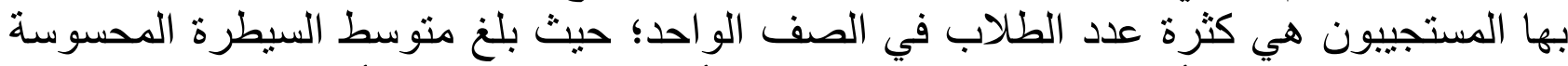

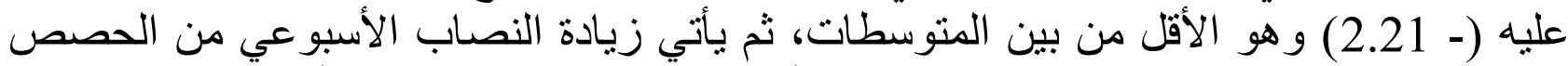

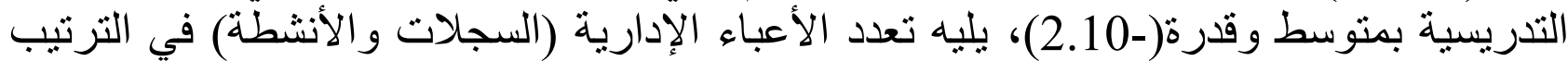

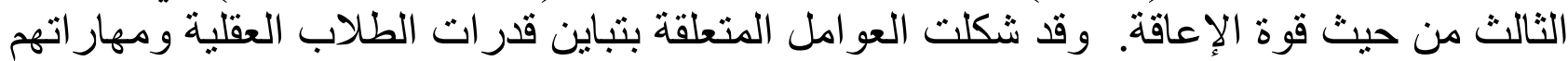

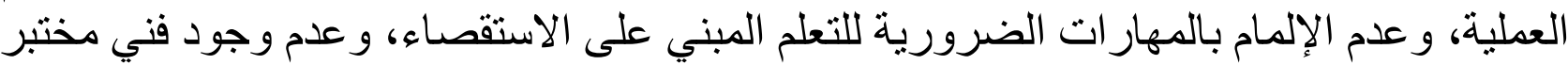

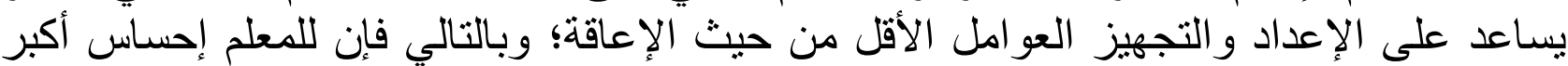
بإمكانية السيطرة عليها.

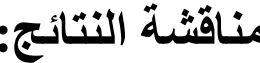

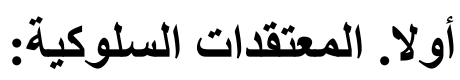

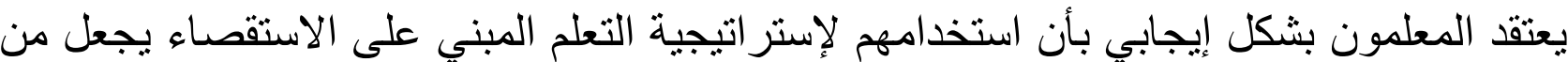

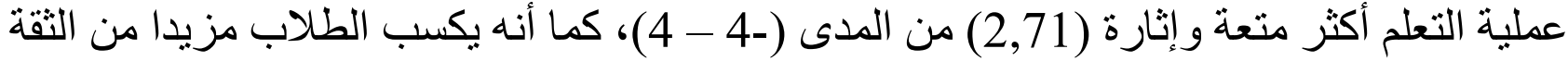

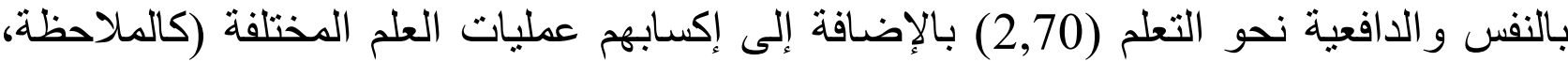

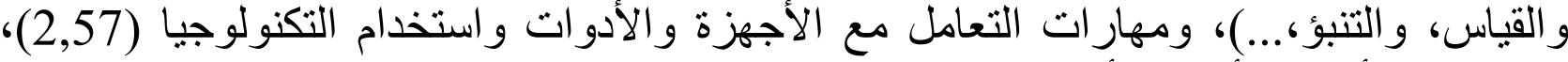
وتحقيق فهم أسر ع وأعمق و أكثر ثباتا لدى الطلاب (2,43)، مع إكسابهم مهار ات اجتماعية مناسبة 


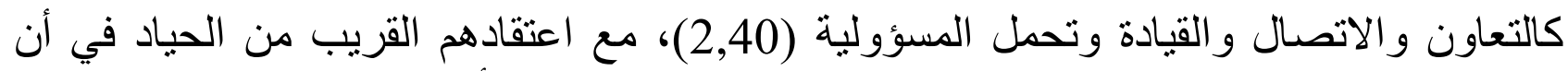

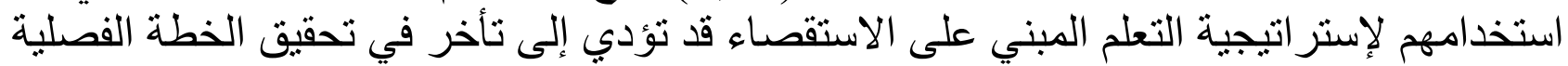

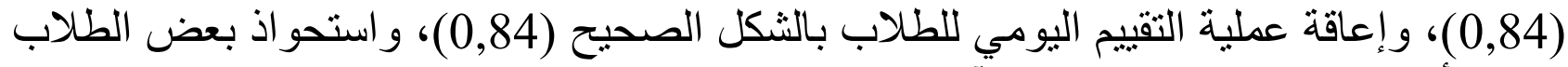

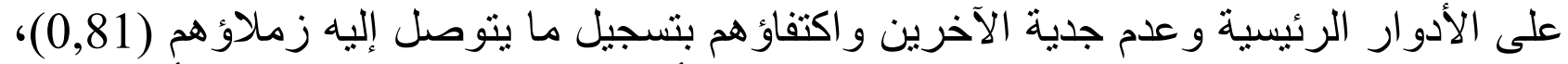

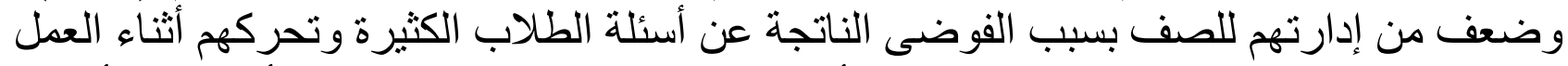

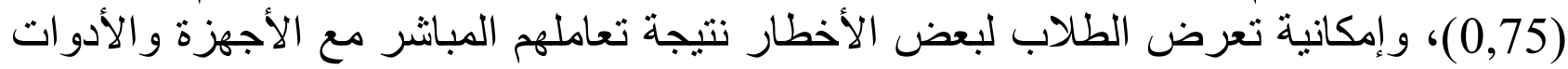

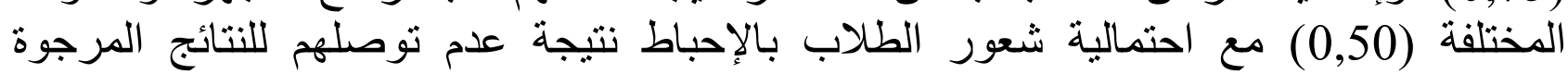

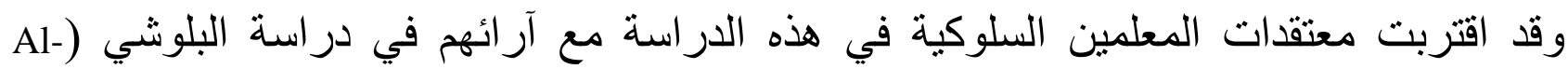

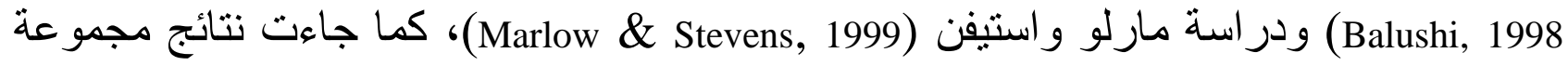
من الدراسات التجريية لاستخدام إستراتيجية التعلم المبني على الاستقصاء مثل (

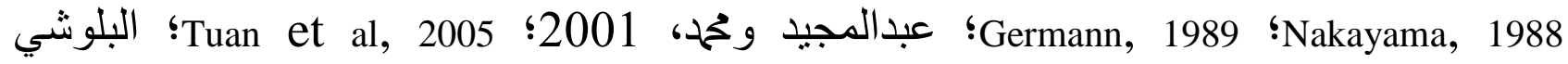
و المقبالي، 2006) منو افقة مع ما يعتقده المعلمون في النتائج الإيجابية المترنبة على استخدامهم

وقد لمس الباحث من خلال عدد من المقابلات الثخصية التي أجر اها مع المعلمين وجود ميل نحو التهاء

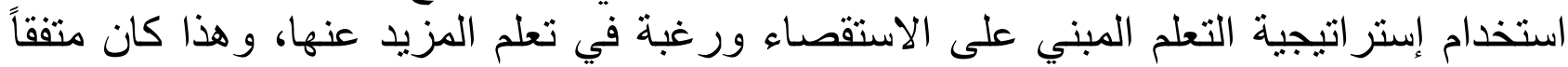

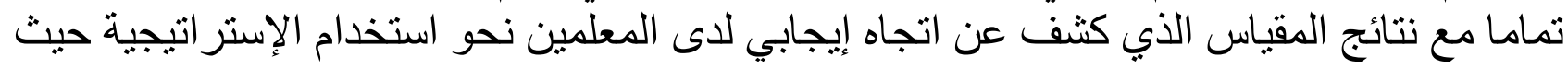

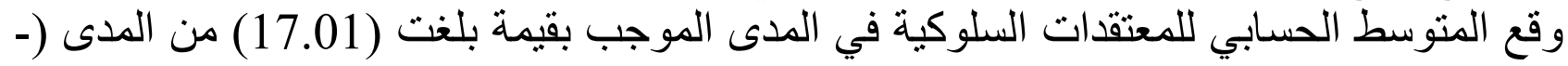

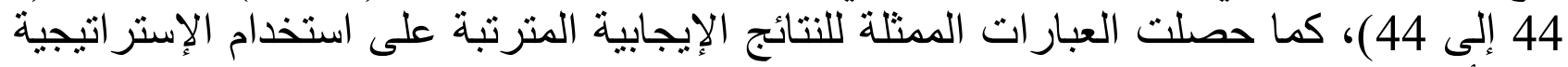

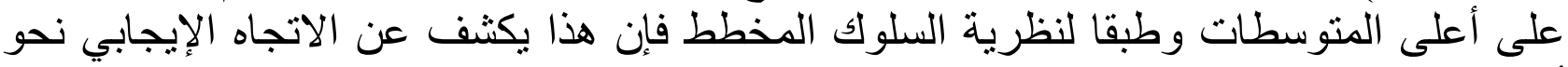

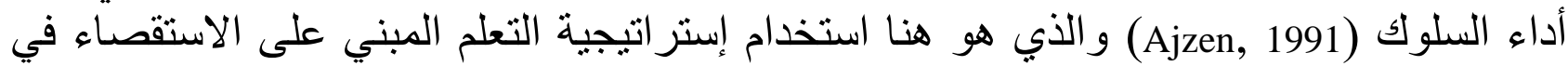

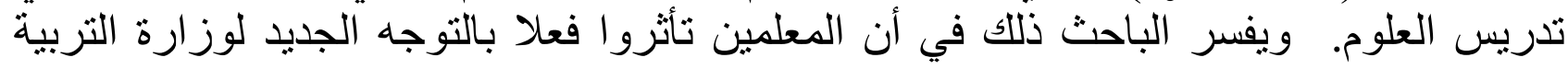

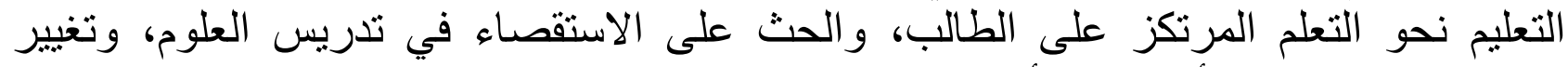

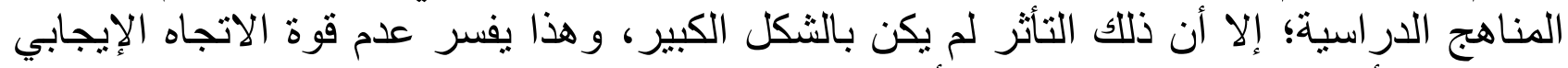

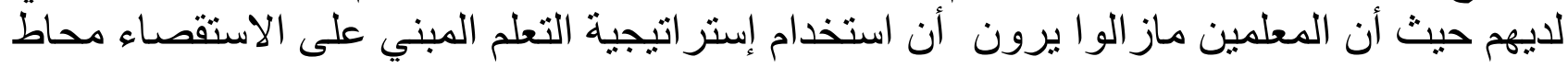

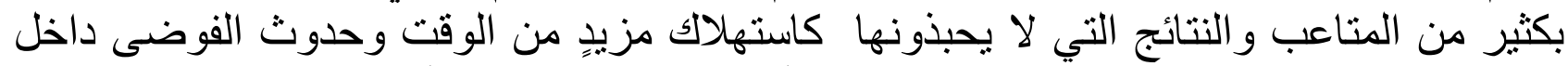

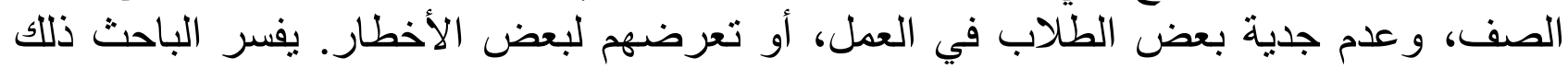
خلال عدد من النقاط، يمكن إيجاز ها في ما يلي في الئي:

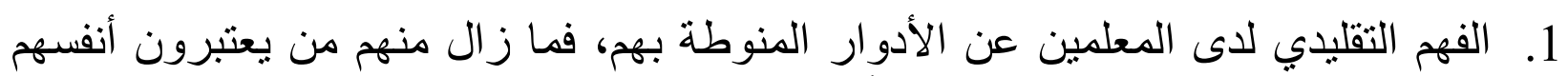

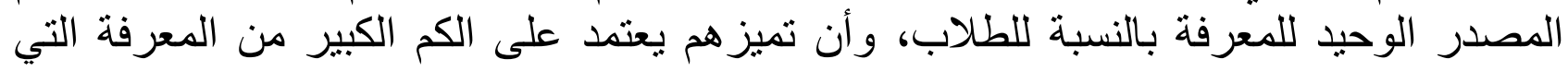
يقدمونها للطلبة.

2. لا يثق بعض المعلمين بقدرات طلابهم العقلية ومهار اتهم اليدوية، ويعتبرون أنفسهم أوصباء

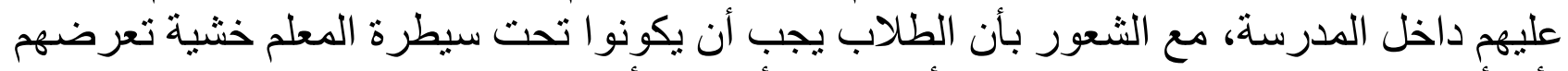
لأي أذى قد يعرضهم للمساءلة الإدارية أو مساءلة أولئة أولياء الأمور .

3. الحساسية المفرطة لدى بعض المعلمين من ارتفاع أصوات الطلاب أو تحركهم داخل الصف لأي سبب من الأسباب، حيث يعنبرون ذلك مساسا بسلطتهم وطعنا في قدرتهم على الإدارة. 


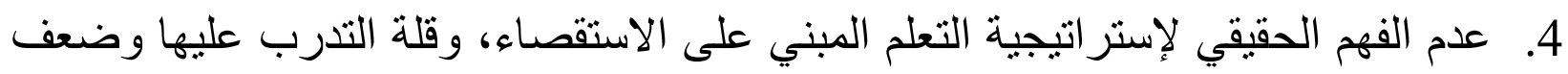

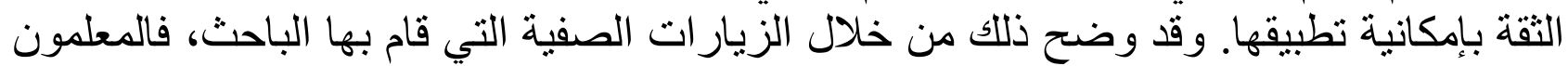
يحاولون تطبيق إرشادات وخطوات دليل المعلم وكتاب الطالب دون إدرات الك عميق لها، فعلى سبيل

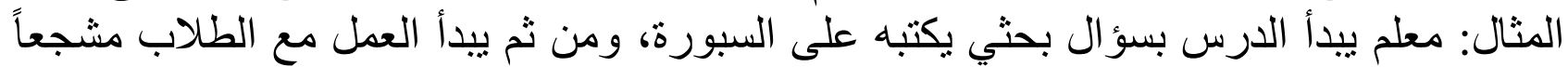

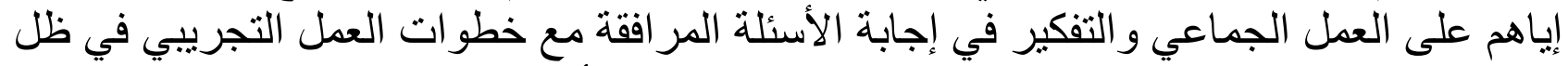

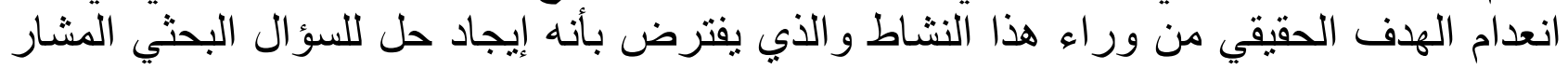

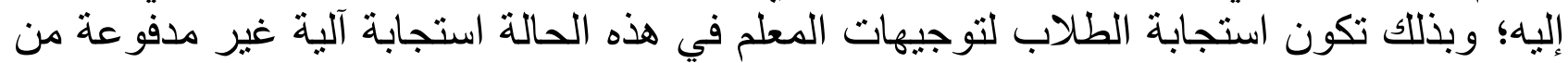

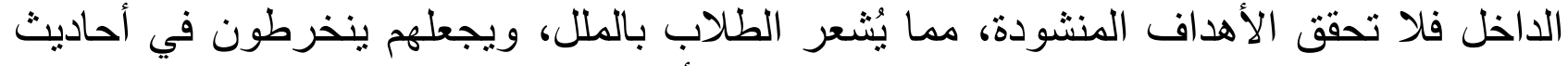

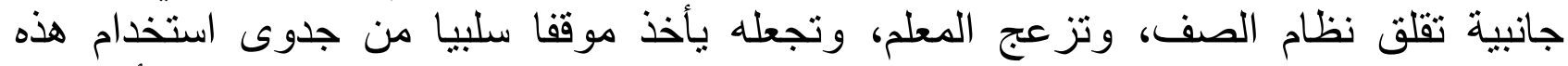

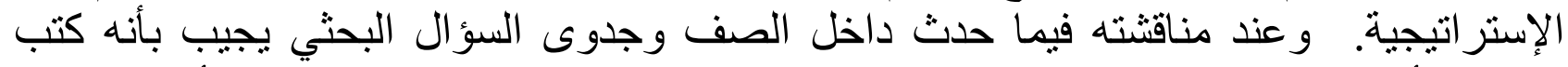

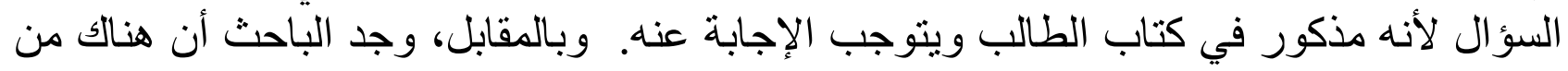

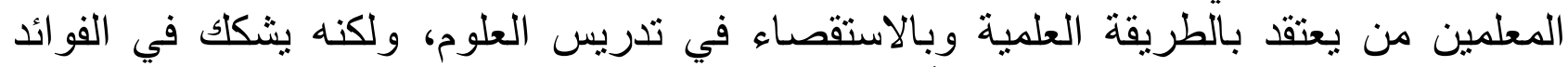

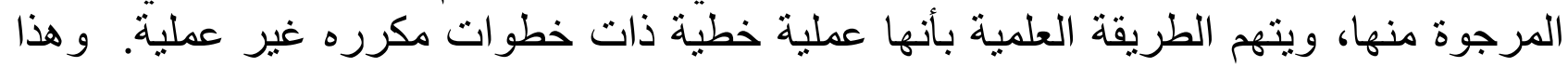
يؤكد ما وصل إليه الباحث من فهم سطحي جدا لدى المعلمين حول إستر اتيجية التعلم المبني على خلى ذان الاستقصاء.

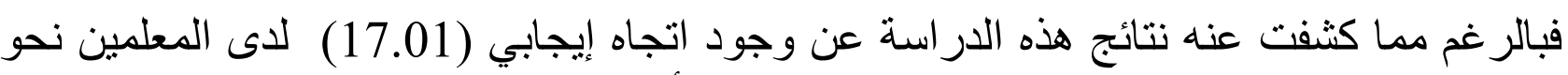

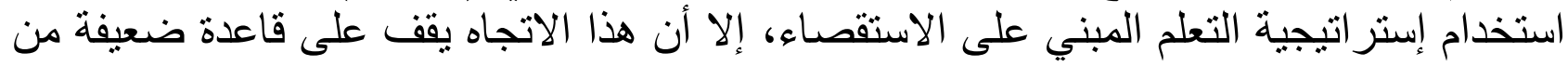

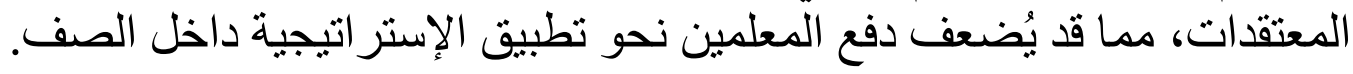
ثانيا. المعتقات المعيارية: كثفت نتائج الدراسة عن وجود درجة متوسطة من التأثز الإيجابي نحو استخدام إستر اتيجية التعلم

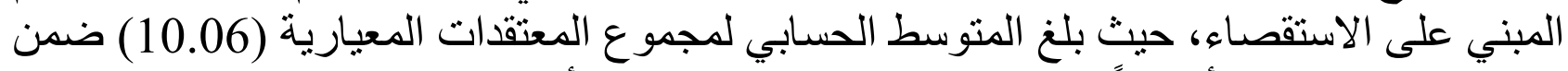

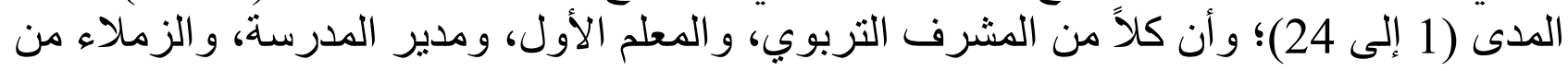

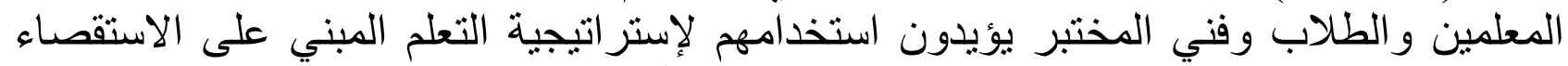

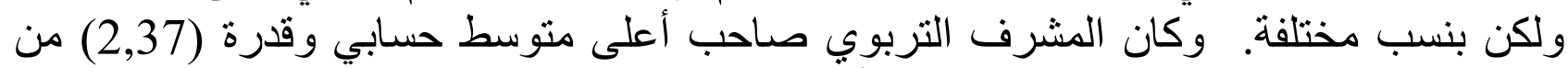

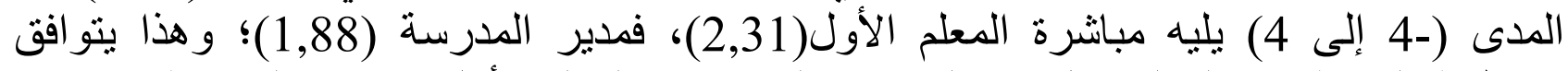

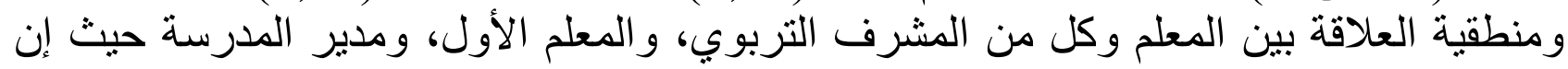

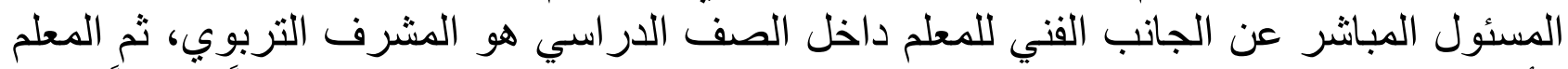

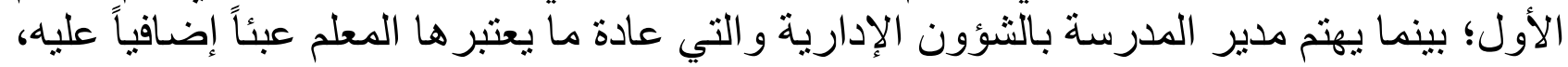
مما يقلل من دافعيته نحو الامتثال لمدير المدرسة. لمون.

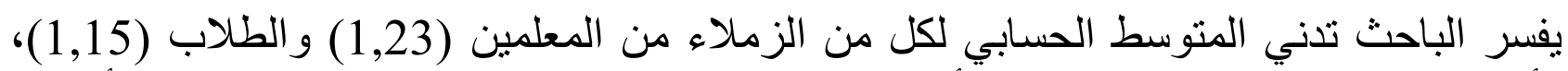

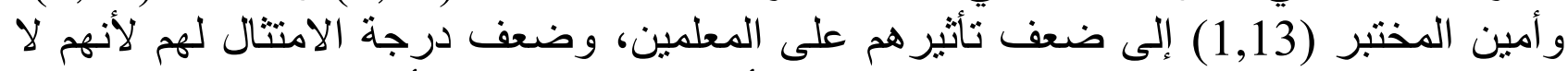

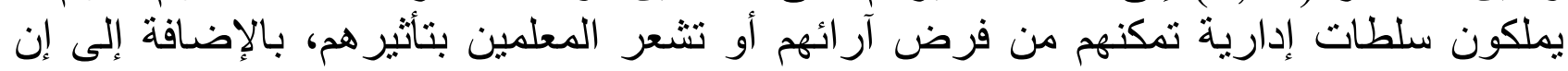

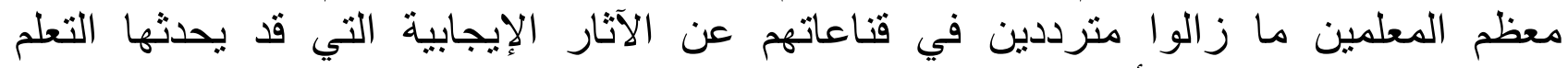

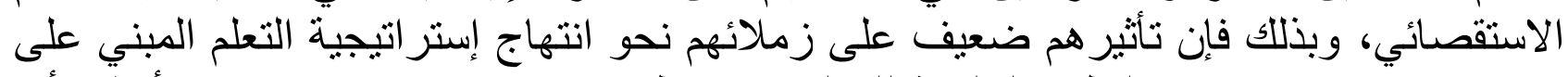

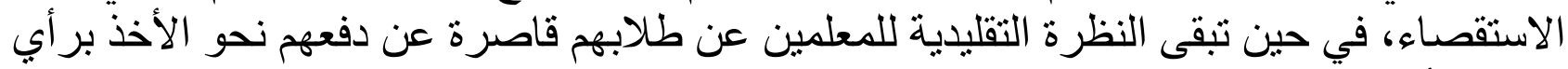

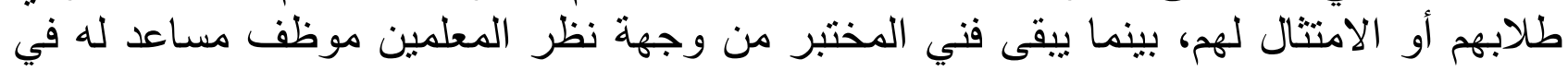


تجهيز الأدوات، والتحضير للتجربة، ومضطر للتعامل مع جميع معلمي العلوم في المدرسة مع وأل

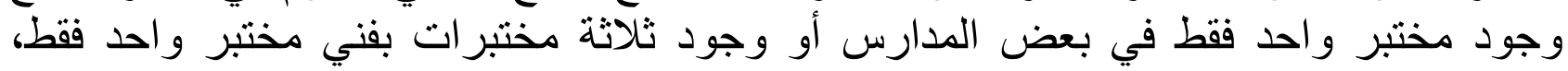

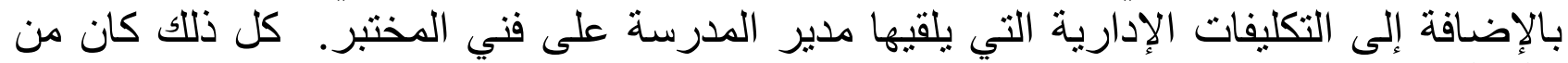

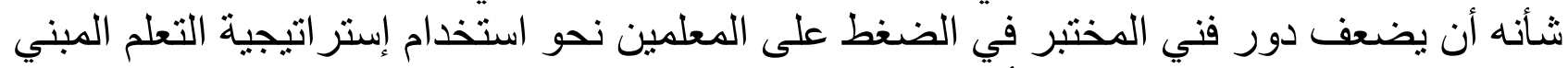

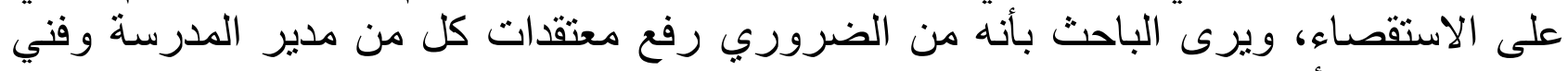

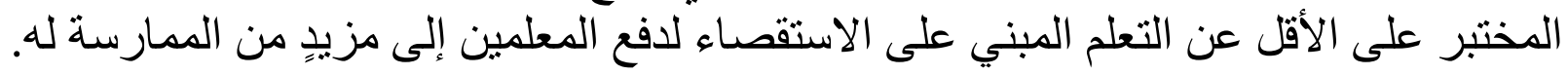

كثالثار معتقدات السيطرة:

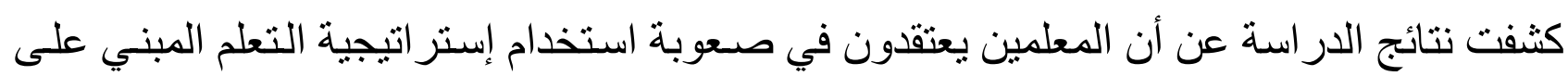

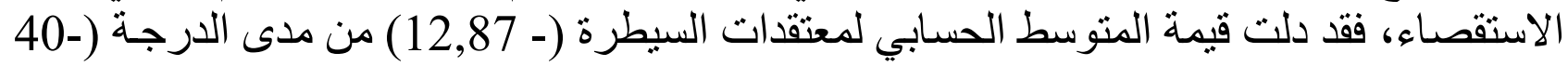

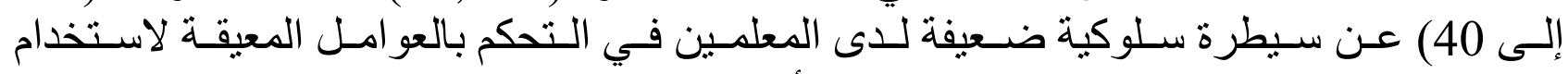

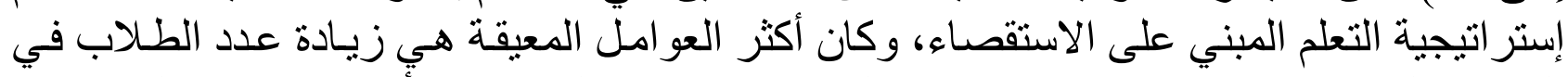

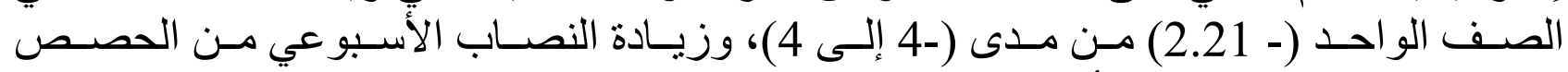

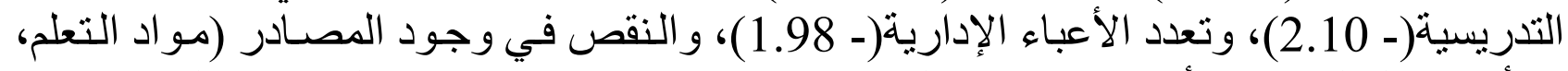

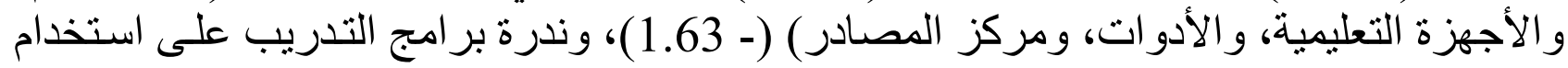

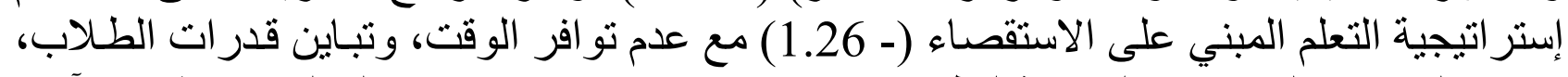

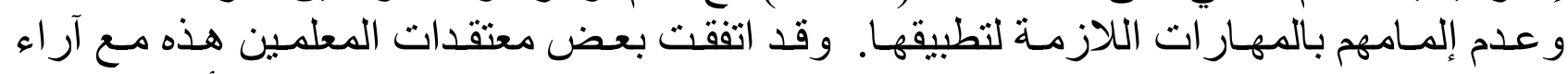

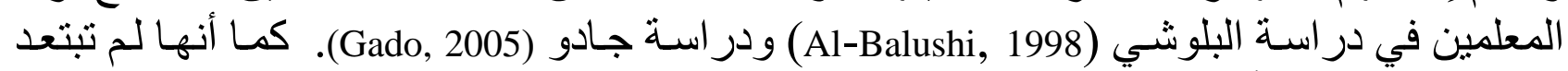

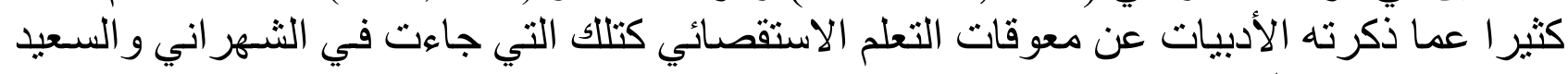

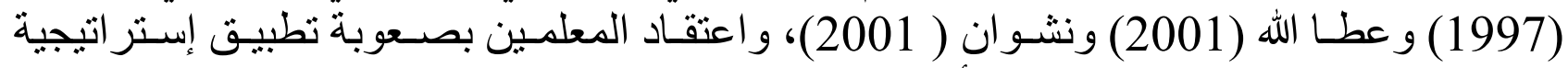

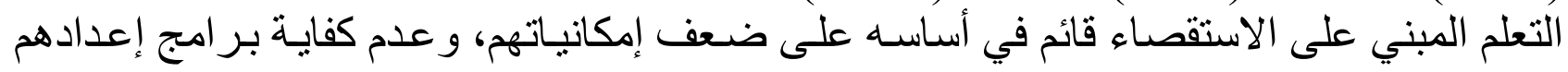

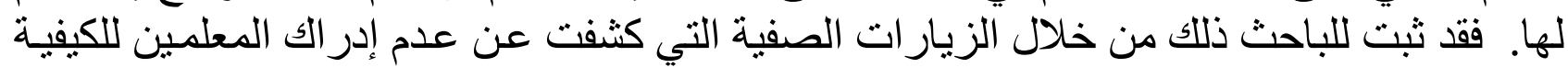

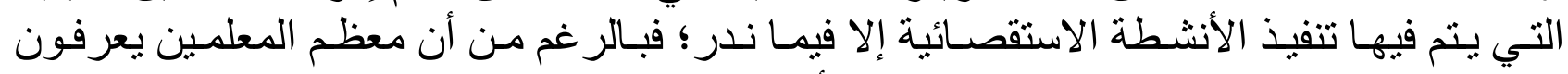

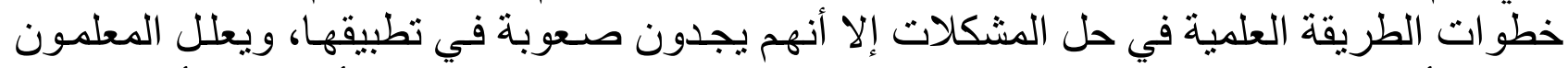

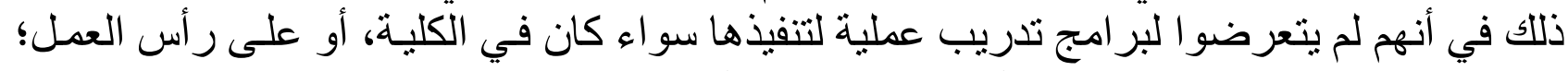

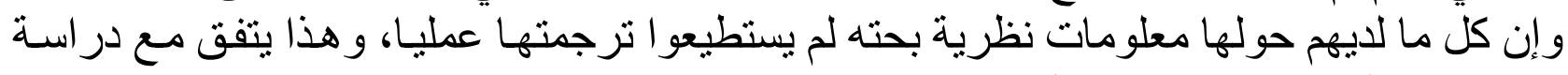

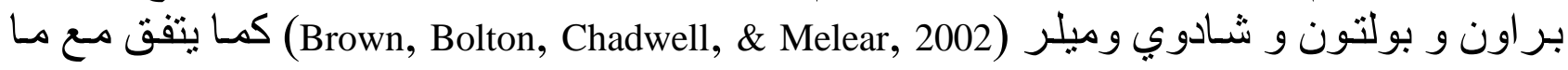

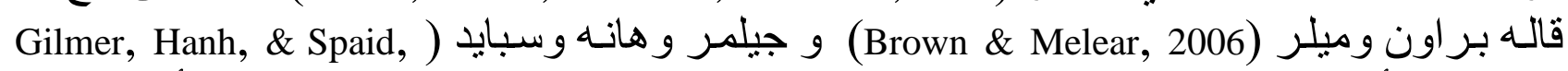

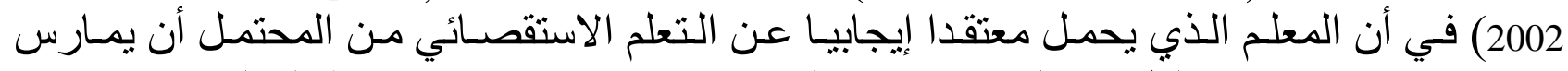

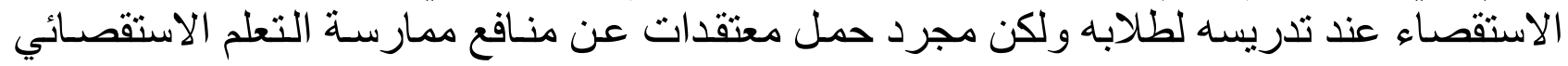

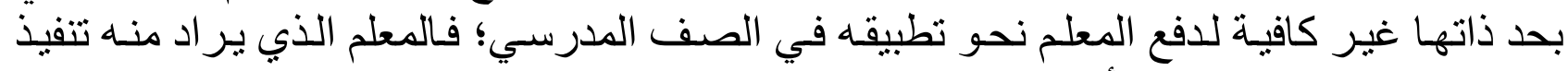

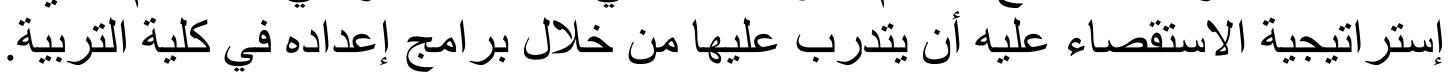

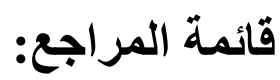
البلوشي، سليمان و المقبالي، فاطمة. (2006) أثر التدريب على تصميم جدول الاستقصاء في تدريس العلوم علي التئي

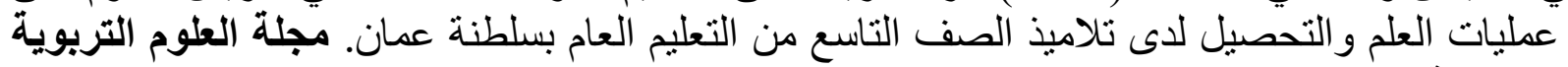
والنفسية. جامعة البحرين، 7 (1): 44-61. 
حمامة، صلاح الدين محمد سليمان. (1995). أثر معتقدات معلمي العلوم حول الطرق الاستقصائية على تحصيل

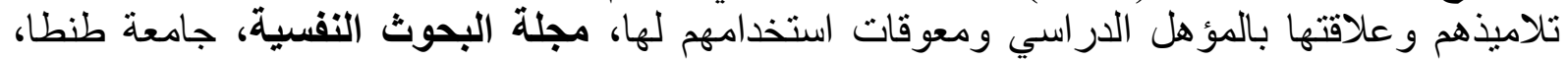

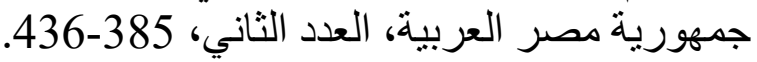
خطايبة، عبدالله.(2005) تعليم العلوم للجميع. عمّان: دار المسيرة. دانيلسون، شارلوتي. (2001) مهنة التدريس ممارستها وتعزيزها (إطار نموذجي). (ترجمة عبدالعزيز بن سعود العمر). الرياض : مكتب التربية العربي لدول الخليج. مهن.

الزدجالي، احلام احمد. (2006) معتقدات معلمي العلوم عن التدريس في ضوء النظرية البنائية وعلاقتها

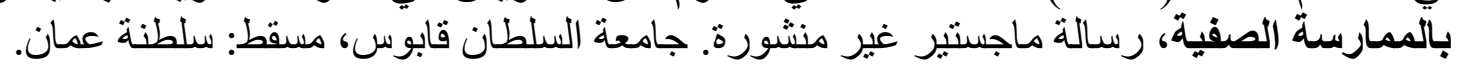

الثهر اني، عامر عبدالله؛ والسعيد، سعيد حمد ـ (1997) تدريس العلوم في التعليم العام. المملكة العربية السعودية: النشر العلمي و المطابع.

عبدالرحمن، سعد. (1983). السلوك الإنساني تحليل وقياس المتغيرات.(الطبعة الثالثة). الكويت: مكتبة الفلاح. عبدالمجيد، ممدوح ححم. و مححد، آمال ربيع كامل (2001) فعالية أنشطة عملية استقصائية مقترحة مفتوحة النهاية

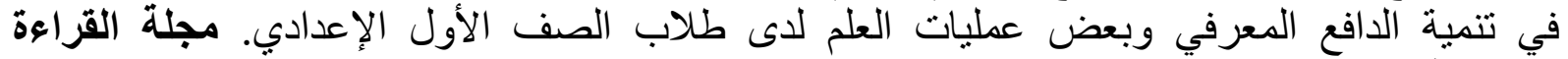
والمعرفة، كلية التربية، جامعة عين شمس، بوفي يوليو العدد الثامن، 205 - 234

عطا الله، ميشيل كامل (2001). طرق وأساليب تدريس العلوم. الطبعة الأولى، عمّان الأردن: دار المسيرة للنشر و التوزيع و الطباعة.

الغافري، علي. (2004) أثر النموذج البنائي (CLM) على التحصيل في الكيمياء والتفكير الابداعي لأى طلبة

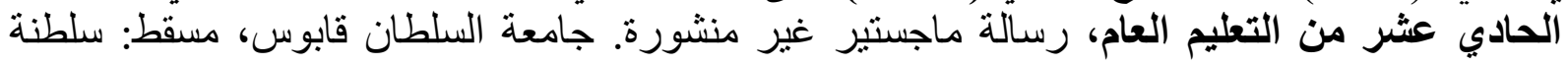
عمان.

فرج، ححه ؛ سلامة، عبدالرحيم ؛ الميهي، رجب. (1999) إتجاهات حديثة في تعليم وتعلم العلوم. الطبعة

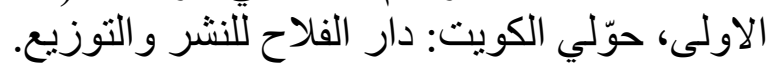

فضل، نبيل ؛ اليماني، سعيد .(1997) بروفيل الاعتقادات العلمية لمعلمي العلوم بدولة البحرين ـ المجلة

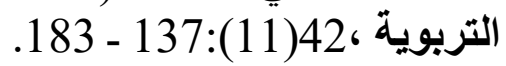

الفنيش، احمد علي. (1975) التربية الاستقصائية لبييا : الدار العربية للكتاب. المري، مباركة الأكرف. (2000). بروفيل الاعتقادات العلمية لدى الطالبات المعلمات في تخصص البص العلوم

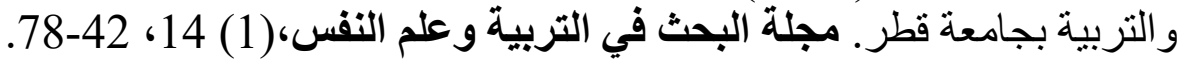
نشوان، بعقوب حسين. (2001) الجديد في تعليم العلوم. الطبعة الأولى: دار الفرقان.

\section{ARABIC REFERENCES IN ROMAN ALPHABET}

Albilushiu, Sulayman Walmuqbaali, Fatmut. (2006). 'Athara Altadrib Ealaa Tasmim Jadwal Alaistiqsa' fi Tadris Aleulum Ealaa Eamaliat Aleilm Waltahsil Ladaa Talamidh Alsafi Alttasie min Altaelim Aleami Bisiltanat Eumaan. Majalat Aleulum Altarbawiat Walnafsiati. Jamieat Albahrayni, 7 (1): 44-61.

Himamata, Salah Aldiyn Muhamad Saliman. (1995). 'Athar Muetaqadat Muelimi Aleulum Hawl Alturuq Alaistiqsayiyat Ealaa Tahsil Talamidhihim Waealaqatiha Bialmuahil Aldirasii Wamueawiqat Aistikhdamihim Liha, Majalat Albihwth Alnafsiati, Jamieat Tunta, Jumhuriat Misr Alearabiat, Aleadad Althaani, 385-436.

Khitayibat, Eibdalluh.(2005) Taelim Aleulum Liljamie. Emman: Dar Almasirat.

Danilisun, Sharluti. (2001). Mihnat Altadris Mumarasataha Wataeziziha ('litar Namudhjia). (Trajamat Eibdaleziz Bin Sueud Aleamra). Alriyad : Maktab Altarbiat Alearabii Lidual Alkhalij.

Alzadjalay, 'Ahlam Ahmud. (2006) Muetaqadat Muelimi Aleulum Ean Altadris fi Daw' Alnazariat Albinayiyat 
Waealaqatiha Bialmumarasat Alsafiati, Risalat Majstayr Ghyr Manshurati. Jamieat Alsultan Qabus, Masqt: Saltanat Eaman.

Alshahraniu, Eamir Eabdalalh; Walsueid, Saeid Muhamad. (1997). Tadris Aleulum fi Altaelim Aleami. Almamlakat Alearabiat Alsaewdit: Alnashr Aleilmii Walmatabaea.

Eabdalrhmn, Saeid. (1983). Alsuluk Al'iinsaniu Tahlil Waqias Almutaghiirat.(Altabeat Althalth). Alkuyt: Maktabat Alfalah.

Eabdalmjid, Mamduh Muhmd. w Muhamid, Amal Rbye Kamil (2001). Faealiatan 'Anshitatan Eamaliatan Aistiqsayiyatan Muqtarahatan Maftuhat Alnihayat fi Tanmiat Alddafie Almaerifii Wabed Eamaliat Aleilm Ladaa Tullab Alsafi Al'awal Al'iiedadii. Majalat Alqira'at Walmaerifati, Kuliyat Altarbiat, Jamieatan Eayan Shms, Yuliu Aleadad Alththaminu, 205 - 234

Eata Allah, Mishil Kamil (2001). Turuq Wa'asalib Tadris Aleuluma. Altibeat Al'uwalaa, Emman Al'urduna: Dar Almasirat Lilnashr Waltawzie Waltabaeat.

Alghafri, Eali. (2004). 'Athar Alnamudhaj Albanayiy (Clm) Ealaa Altahsil i Alkimia' Waltafkir Alaibdaeii Ladaa Tlbt Alhadi Eshr Min Altaelim Aleami, Risalat Majstayr Ghyrf Manshurati. Jamieat Alsultan Qabus, Masqt: Saltanat Eaman.

Faraj, Muhamad; Salamat, Ebdalrhim ; Almihi, Rajb. (1999). 'litjahat Hadithat fi Taelim Wataelam Aleuluma. Altibeat Alawlaa, Hwwly Alkuayta: Dar Alfalah Lilnashr Waltawzie.

Fadl, Nabil; Alyamani, Saeid. (1997). Birufil Alaietiqadat Aleilmiat Limuelimi Aleulum Bidawlat Albahrayn . Almajalat Altarbawiat ,42(11):137 183.

Alfanish, 'Ahmad Eali. (1975). Altarbiat Alaistiqsayiya .Lybia : Aldaar Alearabiat Lilkitab. Almariu, Mubarakat Al'akrif. (2000). Birawfayl Alaietiqadat Aleilmiat Ladaa Altaalibat Almuealamat fi Tukhasas Aleulum Waltarbiat Bijamieat Qatr. Majalat Albahth fi Altarbiat Waealam Alnafs,(1) 14, 42-78.

Nashwan, Yaequb Husayn. (2001). Aljadid fi Taelim Aleulumi. Altibeat Al'uwlaa: Dar Alfurqan.

\section{REFERENCES}

Ajzen, I. (1985). From intentions to actions: A theory of planned behavior. In: J. Kuhl and J. Beckman (Eds.), Action control: From cognition to behavior (pp.11-39). Berlin: Springer-Verlag. (Electronic version).

Ajzen, I. (1988). Attitudes, personality, and behavior. Chicago: The Dorsey Press. (Electronic version).

Ajzen, I. (1991) The theory of planned behavior. Organizational Behavior and Human Decision Processes. $50,179-211$.

Ajzen, I. (2006) Constructing a TpB Questionnaire: Conceptual and Methodological Considerations. (Electronic version) Retrieved February,5,2006, from Word wide: from, http://www.people.umass.edu/aizen/index.html.

Ajzen, I, \& Fishbein, M. (1980). Understanding attitudes and predicting social behavior. Englewood-Cliffs, NJ: Prentice-Hall.

Al-Balushi, S.M. (1998). Science teachers' perception regarding the integration of both inquiry and science application approaches into their laboratory activities. Unpublished Masters Thesis, University of lowa, lowa city, USA.

Borg, M. (2001). Teachers' beliefs. English Language Teaching Journal (ELT Journal), 55 (2) ,186-187.

Brown, S.L., Bolton, K., Chadwell, N., \& Melear, C.T. (2002). Pre-service secondary science teacher apprenticeship experience with scientists. (ERIC Document Reproduction Service No. ED 465 610).

Brown, S. L \& Melear, C. T. (2006) Investigation of Secondary Science Teachers' Beliefs and Practices after Authentic Inquiry-Based Experiences, Journal of Research in Science Teaching, 43 (9): 938-962.

Colburn, A. (2000). An inquiry primer. Science Scope, 42-44. Retrieved March , 18,2005, from Word wide: www.nsta.org/main/news/pdf/ss0003_42.pdf.

Gado, I (2005). Determinant of k-2 school teachers orientation towards inquiry-based science activities: A mixed method study, International Journal of science and Mathematics Education, (3), 511-539.

Donaghue, H. (2003). An instrument to elicit teachers' beliefs and assumptions. English Language Teaching Journal (ELT Journal), 57/4,344-450. 
Fishbein, M., \& Ajzen, I. (1975). Belief, Attitude, Intention, and Behavior: An Introduction to Theory and Research. Reading, MA: Addison-Wesley.

Ford. M (1994) Teachers beliefs about mathematical problem solving in the elementary school, School Science and Mathematics, 94 (6), 314- 322.

Germann, P. J (1989) Directed-inquiry approach to learning science process skills: treatment effects and aptitude-treatment interactions. Journal of Research in Science Teaching, 26, (3) ,237-250.

Gilmer, P.J., Hahn, L.L., \& Spaid, R.M. (2002). Experiential learning for pre-service science and mathematics teachers: Applications to secondary classrooms. Tallahassee, FL: SERVE.

Grawley, F. E. (1990). Intentions of science teachers to use investigative teaching methods: A test of the theory of planned behavior. Journal of Research in Science Teaching, 27(7), 685-697.

Jarrett, D. (1997). Inquiry Strategies for Science and Mathematics. Portland: Northwest Regional Educational Laboratory. (Electronic version).

Llewellyn, D. (2001). Inquiry within: Implementing inquiry-based science standards. Thousand Oaks, CA: Corwin Press, Inc.

Lumpe, A. T; Haney, J. J \& Czerniak, C. M. (1998). Science teacher beliefs and intentions regarding the use of cooperative learning, Journal of Research in Science Teaching, 98 (3) ,123-135

Lumpe, A. T; Haney, J. J \& Czerniak, C. M. (2000). Assessing teachers' beliefs about their science teaching context. Journal of Research in Science Teaching, 37(3) ,275-292.

Marlow, M P.; Stevens, E. (1999) Science teachers attitudes about inquiry-based science, (ERIC Document Reproduction Service No. ED 466 350).

Mattheis, F. E \& Nakayama, G (1988) Effects of laboratory-centered inquiry program on laboratory skills, science process skills and understanding of science knowledge in middle grades students. (ERIC Document Reproduction Service No. ED 307148).

National Research Council. (NRC) (1996). National Science Education Standards. Washington, DC: National Academies Press.

National Research Council. (NRC) (2000). Inquiry and the National Science Education Standards. Washington, DC: National Academy Press.

Staten, M. E. (1998) Action research study. A framework to help move teachers toward an inquiry - based science teaching approach, (ERIC Document Reproduction Service No. ED 429049).

Tuan, H; Chin, C; Tsai, C \& Cheng, S. (2005) Investigating the Effectiveness of Inquiry Instruction on the Motivation of Different Learning Styles Students. International Journal of Science and Mathematics Education, 3, (4), 541-566.

Wenning, C.J. (2005). Levels of inquiry: Hierarchies of pedagogical practices and inquiry processes. Journal of Physics TeacherEducationOnline,2(3),311. Retrieved: august, 2, 2006, from the world wide web: http://phy.ilstu.edu/pte/publications/levels_of_inquiry.pdf. 